\title{
A CONCEPT FOR THE INTRINSIC DIELECTRIC STRENGTH OF ELECTRICAL INSULATION MATERIALS
}

By

E. F. Cuddihy

April 15, 1985

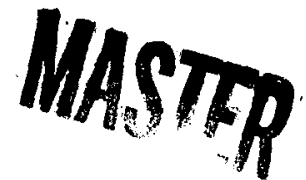

Work Performed Under Contract No. Al01-76ET20356

Jet Propulsion Laboratory

Pasadena, California

Technical Information Center

Office of Scientific and Technical Information United States Department of Energy 


\section{DISCLAIMER}

This report was prepared as an account of work sponsored by an agency of the United States Government. Neither the United States Government nor any agency thereof, nor any of their employees, makes any warranty, express or implied, or assumes any legal liability or responsibility for the accuracy, completeness, or usefulness of any information, apparatus, product, or process disclosed, or represents that its use would not infringe privately owned rights. Reference herein to any specific commercial product, process, or service by trade name, trademark, manufacturer, or otherwise does not necessarily constitute or imply its endorsement, recommendation, or favoring by the United States Government or any agency thereof. The views and opinions of authors expressed herein do not necessarily state or reflect those of the United States Government or any agency thereof.

This report has been reproduced directly from the best available copy.

Available from the National Technical Information Service, U. S. Department of Commerce, Springfield, Virginia 22161.

Price: Printed Copy A04

Microfiche A01

Codes are used for pricing all publications. The code is determined by the number of pages in the publication. Information pertaining to the pricing codes can be found in the current issues of the following publications, which are generally available in most libraries: Energy Research Abstracts (ERA); Government Reports Announcements and Index (GRA and I); Scientific and Technical Abstract Reports (STAR); and publication NTIS-PR-360 available from NTIS at the above address. 


\section{DISCLAIMER}

This report was prepared as an account of work sponsored by an agency of the United States Government. Neither the United States Government nor any agency Thereof, nor any of their employees, makes any warranty, express or implied, or assumes any legal liability or responsibility for the accuracy, completeness, or usefulness of any information, apparatus, product, or process disclosed, or represents that its use would not infringe privately owned rights. Reference herein to any specific commercial product, process, or service by trade name, trademark, manufacturer, or otherwise does not necessarily constitute or imply its endorsement, recommendation, or favoring by the United States Government or any agency thereof. The views and opinions of authors expressed herein do not necessarily state or reflect those of the United States Government or any agency thereof. 


\section{DISCLAIMER}

Portions of this document may be illegible in electronic image products. Images are produced from the best available original document. 
DOE/JPL/1012-105

(JPL-PUB-85-30)

(DE85014497)

Distribution Category UC-63b

\title{
A Concept for the Intrinsic Dielectric Strength of Electrical Insulation Materials
}

\author{
E.F. Cuddihy
}

April 15, 1985

Prepared for

U.S. Department of Energy

Through an Agreement with

National Aeronautics and Space Administration

by

Jet Propulsion Laboratory

California Institute of Technology

Pasadena, California

JPL Publication $85 \cdot 30$

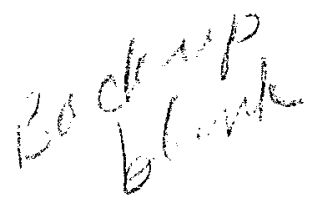




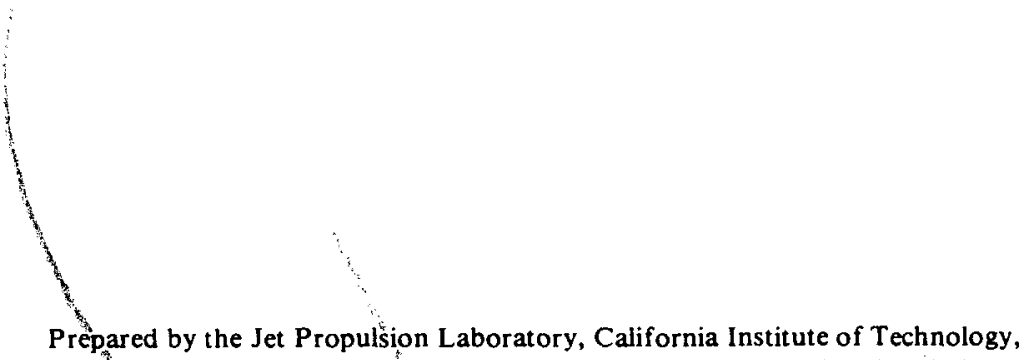
for the U.S. Department of Energy through an agreement with the National Aeronautics and Space Administration.

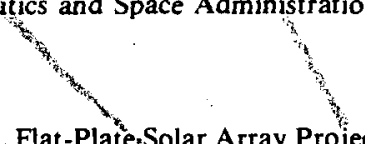

The JPL Flat-Plate-Solar Array Project is sponsored by the U.S. Department of Energy and is part of the National Photovoltaics Program to initiate a major effort toward the development of cost-competitive solar arrays.

This report was prepared as an account of work sponsored by an agency of the United States Government. Neither the United States Government nor any agency thereof, nor any of their employees makes any warranty, express or implied, or assumes any legal liability or responsibility for the accuracy, completeness, or usefulness of any information, apparatus, product, or process disclosed, or represents that its use would not infringe privately owned rights.

Reference herein to any specific commercial product,"process, or service by trade name, trademark, manufacturer, or otherwise, does not necessarily constitute or imply its endorsement, recommendation, or favoring by the United States Government or any agency thereof. The views and opinions of authors expressed herein do not necessarily state or reflect those of the United States Government or any agency thereof.

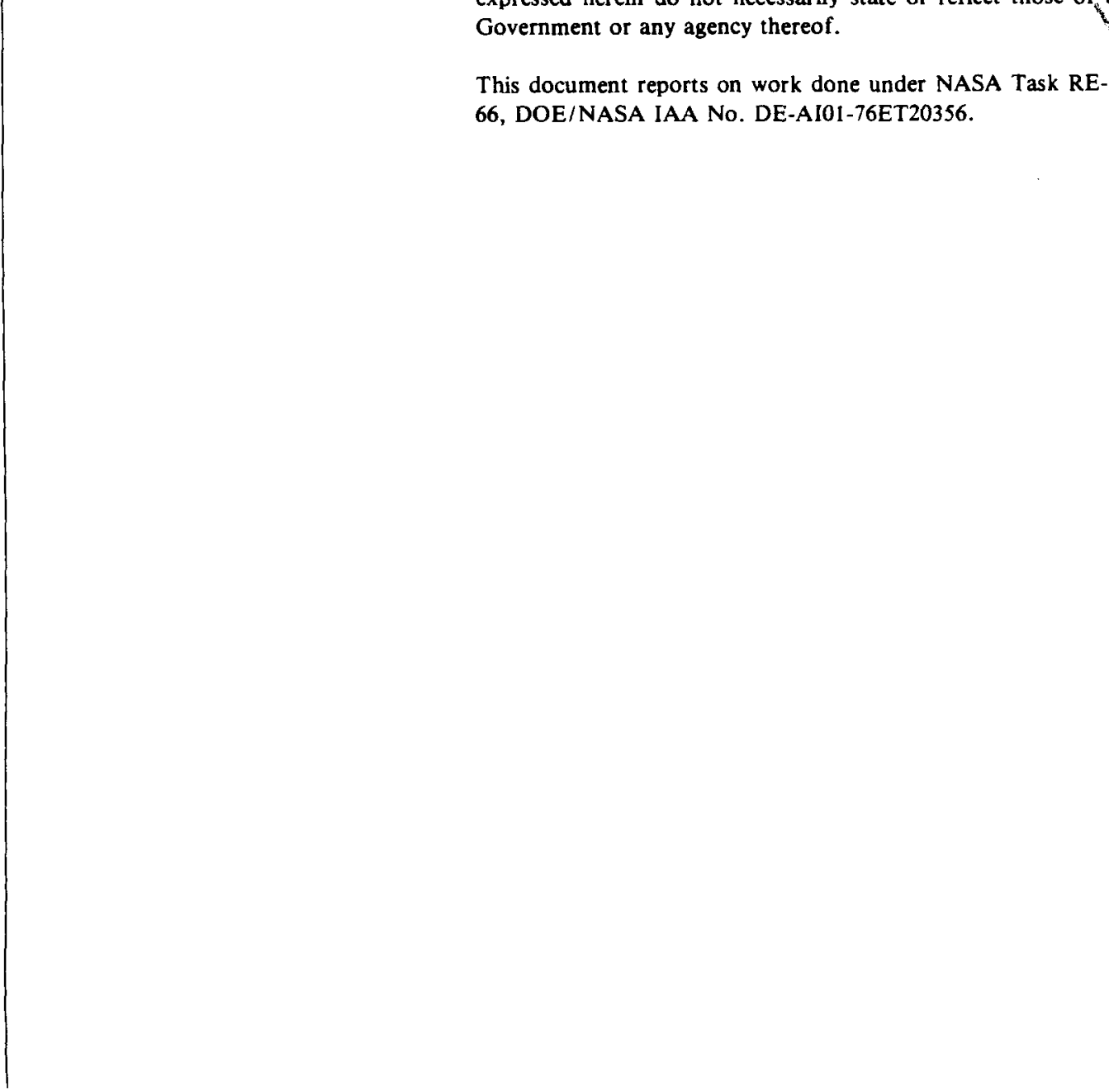

Amendment 
A concept is described for a possible definition of the intrinsic dielectric strength of insulating materials, which can be considered as a fundamental material property similar to other material properties, such as Young's modulus, index of refraction, and expansion coefficients. The events leading to the recognition of this property are reported, and the property is defined. This intrinsic dielectric strength concept should facilitate interpretation of results from accelerated and/or natural aging programs intended to predict electrical insulation service 1 ife of encapsulants in photovoltaic modules. As a practical application, this new concept enabled a possible explanation of the cause of failures in buried high-voltage cables with polyethylene insulation, and a possible explanation of the causes of electrical trees in polyethylene; these also are described. 

7 
The author thanks John Winslow, Ron Ross, Gordon Mon, and Carl Solloway of the Jet Propulsion Laboratory for their positive contributions to and commentaries on the technical scope and mathematical content of this document. 
CONTENTS

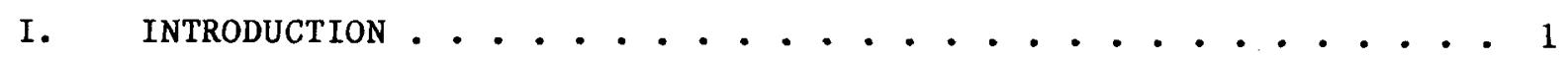

II. THE VOLTAGE GRADIENT

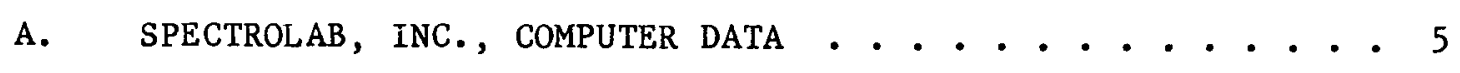

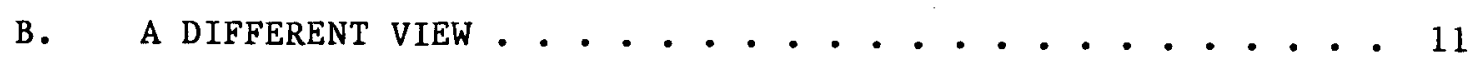

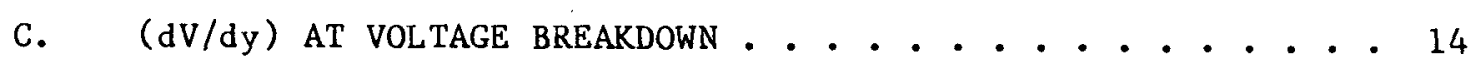

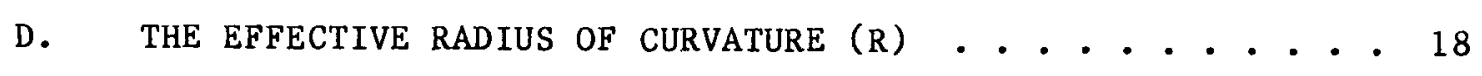

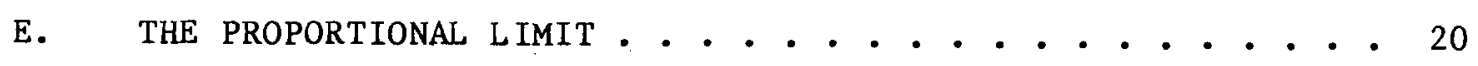

F. POLYETHYLENE-INSULATED CABLES • • • • • • • • • • • • • •

1. Orientation . . . . . . . . . . . . . . . 21

2. Proportional Limit . . . . . . . . . . . . 25

3. Effect of Water . . . . . . . . . . . . . 27

4. Buried Cable . . . . . . . . . . . . . . . 28

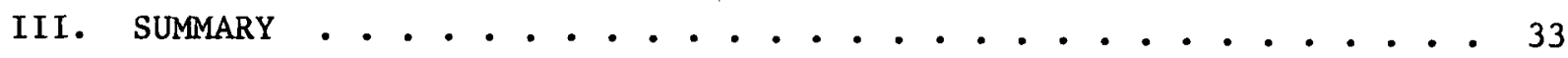

IV. REFERENCES • • • • • • • • • • • • • • • • • • . • . . . 35

APPENDIX

A. SERIES EXPANSIONS OF THE TIP-TO-TIP AND TIP-TO-GROUND

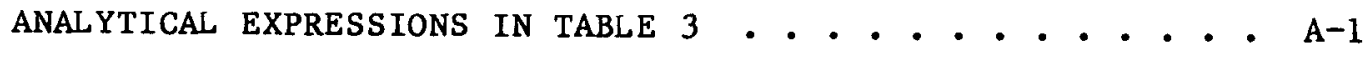

\section{Figures}

1. Construction Elements of Photovoltaic Encapsulation Systems

2. Encapsulation Solar-Cell Geometry (Analyzed

by Spectrolab, Inc.) ....... . . . . . . . . 5

3. Plot of Data in Table 2.............. 7

4. Linear-Linear Plot of Table 2 Data as $\mathrm{V}_{\mathrm{A}} /(\mathrm{dV} / \mathrm{dy})_{\mathrm{MAX}}$

Versus the Variable $2 R /(t+2 R) . . . . . . . . . . . .8$ 
5. Log-Log Plot of Table 2 Data as $\mathrm{V}_{\mathrm{A}}(\mathrm{dV} / \mathrm{dy}) \mathrm{MAX}$

Versus the Variable $2 R /(t+2 R)$........... 9

6. Dielectric Strength of PMMA Acrylic .......... 10

7. Dielectric Strength of Ethylene Vinyl Acetate . . . . . 15

8. Dielectric Strength of Polyethylene .......... 17

9. Symmetric and Asymmetric Electrode Pairings ....... 19

10. Dependence of Average Breakdown Voltage $\mathrm{V}_{\mathrm{A}}$ of Embedded Needle Electrodes at $60^{\circ} \mathrm{C}$ (Figure $7 \mathrm{~b}$ in Reference 6) .. 19

11. Comparative Stress/Strain Plots . . . . . . . . 20

12. Significance of the Proportional Limit . . . . . . . 22

13. Devices Used by Researchers Before 1950 to Prepare

Recessed Test Specimens for Electrical-Property

Testing (Figures 1 and 2 in Reference 17) ........ 24

14. Representative Illustration of the Linear Relationship

Between Breakdown Voltage and Sample Thickness, Using

Recessed Specimens (After Figure 7, Reference 17) . . . 25

15. Dielectric Strength of Mylar Film Material at Various

Humidities (After Du Pont Co. Technical Bulletin M-4D,

"Electrical Properties of Mylar Polyester Film") . . . . . 28

16. Effect of Electrode Size on Dielectric Strength of Mylar

(After Du Pont Co. Technical Bulletin M-4D, "Electrical

Properties of Mylar Polyester Film") . . . . . . . . 31

Tables

1. Encapsulation Pottant Materials for Terrestrial

Photovoltaic Modules............... 2

2. Computer-Generated Values of $(\mathrm{dV} / \mathrm{dy})_{\mathrm{MAX}} / \mathrm{V}_{\mathrm{A}}$ and

$(t / 2 R)$ for the Solar Cell Geometry Illustrated

in Figure 2 ................... 6

3. Analytical Solutions of La Place's Field Equations

for Needle Electrodes . . . . . . . . . . . . 11

4. Average Breakdown Voltage of Ethylene Vinyl Acetate

for Three Film Thicknesses . . . . . . . . . . 15

5. Properties of Polyethylene Resins (Adapted from

Table LXXXI, Reference 23) . . . . . . . . . . 27 
The Jet Propulsion Laboratory (JPL) has been assigned by the U.S. Department of Energy (DOE) responsibility for managing the Flat-Plate Solar Array Project (FSA). This project is responsible for planning and supporting national research programs to reduce the cost of, and to increase the outdoor service life of, terrestrial photovoltaic (PV) modules, with a goal of 30 years of service. One phase of this project is concerned with the development of materials that are to function as low-cost, long-life encapsulants for solar cells (Reference 1 ). Figure 1 illustrates the essential material components of state-of-the-art commercial photovoltaic modules.

The central core of an encapsulation system is the pottant, a transparent, elastomeric material that is the actual encapsulation medium in a module. This material totally encloses and embeds all of the solar cells and

\section{MODULE SUNSIDE LAYER DESIGNATION $\quad$ FUNCTION}

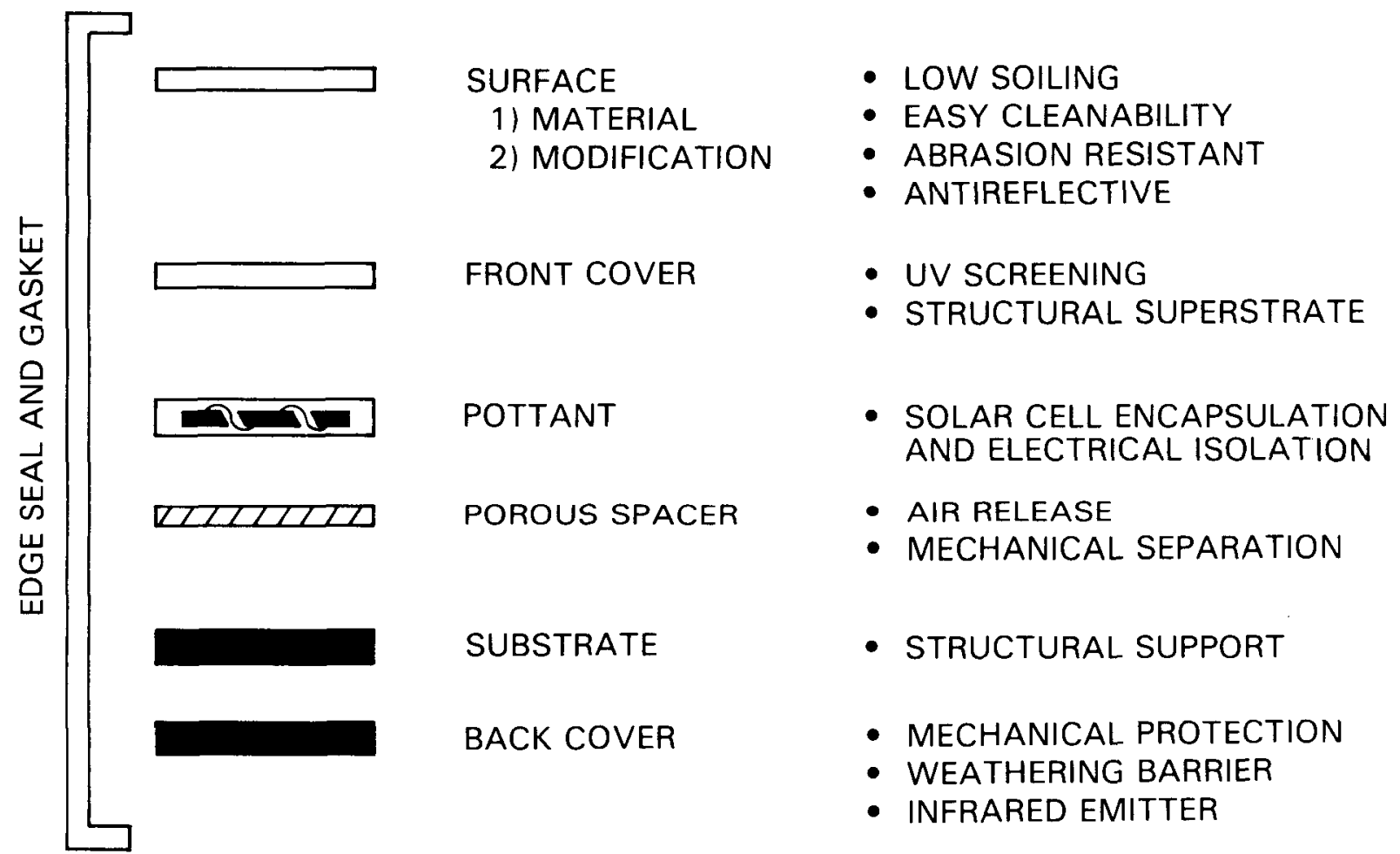

Figure 1. Construction Elements of Photovoltaic Encapsulation Systems 
their associated electrical circuitry; the demands on a pottant material are numerous. Some of the more significant requirements are:

(1) Be highly transparent in the silicon solar-cell response wavelength region of 0.4 to $1.1 \mu \mathrm{m}$.

(2) Function as electrical insulation for isolating high-voltage dc circuitry.

(3) Serve as a mechanical cushioning and stress relief medium for fragile solar cells.

(4) Be readily processed in automated module fabrication.

Table 1 lists the five principal transparent, elastomeric materials now in use commercially or in advanced stages of development for pottant application. Of these five, ethylene vinyl acetate (EVA) is emerging as a dominant pottant material (Reference 2).

With engineering advances leading to reductions in the cost of photovoltaic modules to a current range of $\$ 4$ to $\$ 7$ per peak watt output, these devices are becoming increasingly attractive to electric utilities as alternative sources of commercial power generation. Therefore FSA is becoming increasingly concerned with the long-term (about 30 years) dc electrical insulation qualities of pottant materials such as EVA in outdoor weathering envi ronments.

A review of published literature and journal articles reveals that researchers and workers in the field of electrical insulation have been seeking an understanding of electrical aging mechanisms as well as the development of 1 ife-prediction methodologies (Reference 3 ). But despite considerable progress, there are no immediately available methods or techniques to assess the electrical insulation life potential of materials such as those listed in Table 1.

Table 1. Encapsulation Pottant Materials for Terrestrial Photovoltaic Modules

Ethylene vinyl acetate (EVA)

Poly vinyl butyral (PVB)

Ethylene methyl acrylate (EMA)

Z-2591 Polyurethane (PU)

Poly-n-butyl acrylate (PnBA)
Commercial/developmental

Commercial

Developmental

Commercial

Deve lopmental 
Under FSA research contract, Spectrolab, Inc., a manufacturer of photovoltaic modules, recently developed a computer program to model the level of electrical field intensities and stresses associated with the geometries of encapsulated solar cells (Reference 4). This was part of the FSA technical program related to accelerated aging of encapsulation pottant materials, and knowledge of typical electrical stress levels to which pottants would be subjected in service was sought.

However, a mathematical analysis of the Spectrolab computer data led serendipiditously to an unexpected finding related to the dielectric strength of electrical insulation materials. In essence, it appeared that a fundamental definition of an intrinsic dielectric strength of insulation materials had been identified, which could be stated as a basic material property independent of any test technique or service environment. This is similar to other pure material properties such as Young's modulus, index of refraction, and coefficient of thermal expansion.

This document describes the computer modeling, the mathematical analysis of the computer data, and resultant speculation on intrinsic dielectric strength. The intrinsic dielectric strength concept also provides a fresh perspective on implementing experimental programs related to electrical stress aging. As a practical matter, the intrinsic dielectric strength concept was used theoretically to arrive at a possible explanation of electrical and water trees in the polyethylene insulation of high-voltage cables, and also for a possible explanation of the occurrences of polyethylene insulation failures in buried high-voltage cables.

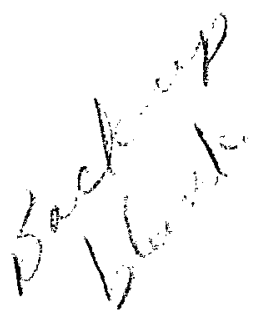





\section{A. SPECTROLAB, INC., COMPUTER DATA}

Figure 2 is an illustration of a solar cell with a rounded edge of radius $R$, encapsulated in a pottant with thickness $t$ isolating the solar cell from an electrically conducting ground plane. The voltage difference between the cell and ground is $\mathrm{V}$, and $\mathrm{y}$ is the dimensional coordinate between the cell and ground. The Spectrolab computer program calculates the maximum electrical voltage gradient, (dV/dy) MAX, that will occur on the rounded edge, as a function of $V, t$, and $R$. It was found for this example that the computer results could be expressed as two dimensionless reduced variables:

$$
(t / 2 R)
$$

and

$$
(\mathrm{dV} / \mathrm{dy})_{\mathrm{MAX}} / \mathrm{V}_{\mathrm{A}}
$$

where $v_{A}$ is the average potential gradient $=(v / t)$. The values of these two reduced variables are given in Table 2 , for the range of $(t / 2 R)$ from 0.25 to 50 .

The data illustrate the field intensification that results on the rounded edge relative to the average potential gradient $V_{A}$ as the solar cell radius $R$ is decreased, and also show that the potential gradient $(\mathrm{dV} / \mathrm{dy})_{\mathrm{MAX}}$ approaches the average potential gradient $V_{A}$ as pottant thickness $t$ decreases.

With these data, an effort was made to combine the two reduced variables in a compact mathematical expression for general utility. The procedure

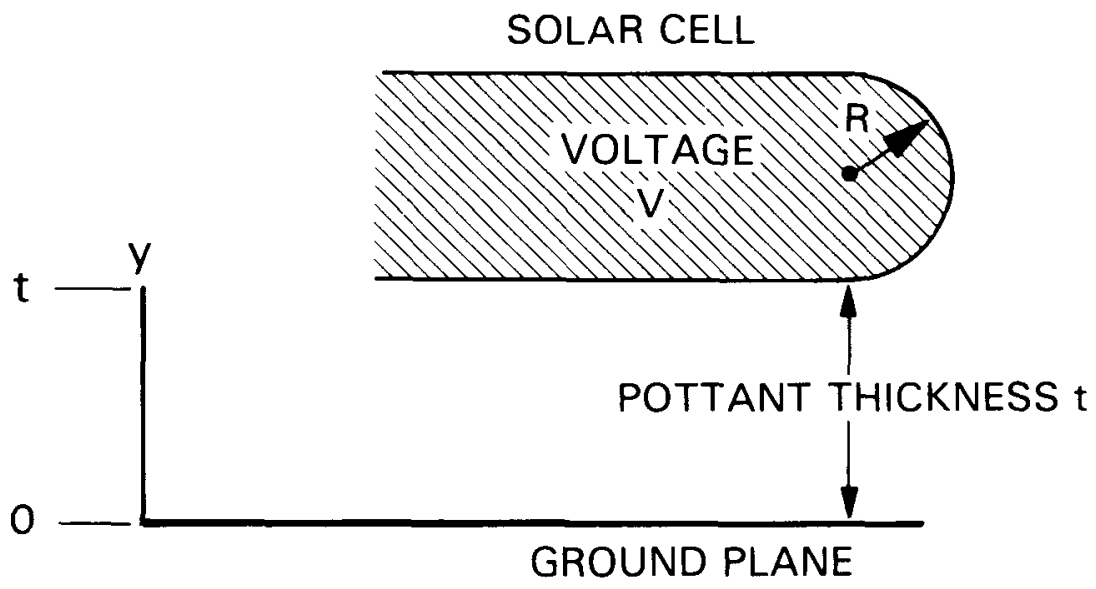

Figure 2. Encapsulated Solar-Cel1 Geometry (Analyzed by Spectrolab, Inc.; Reference 4) 
Table 2. Computer-Generated Values of $(d V / d y)_{M A X} / V_{A}$ and $(t / 2 R)$ for the Solar-Cell Geometry Illustrated in Figure 2

\begin{tabular}{cc}
\hline$(\mathrm{dV} / \mathrm{dy})_{\mathrm{MAX}} / \mathrm{V}_{\mathrm{A}}$ & $(\mathrm{t} / 2 \mathrm{R})$ \\
1.0969 & 0.25 \\
1.2195 & 0.50 \\
1.4277 & 1.00 \\
1.7705 & 2.00 \\
2.5536 & 5.00 \\
3.3692 & 10.00 \\
4.3383 & 20.00 \\
5.2687 & 50.00 \\
\hline
\end{tabular}

involved plotting first the reciprocal of $(d V / d y)_{M A X} / V_{A}$ versus $(t / 2 R)$, i.e., $V_{A} /(d V / d y)_{M A X}$ versus $(t / 2 R)$, as shown in Figure 3 . The data trace in Figure 3 is suggestive of a hyperbola, and therefore the reduced variable $(t / 2 R)$ was recalculated as

$$
\frac{1}{\left(\frac{t}{2 R}+1\right)}
$$

which is equal to

$$
\frac{2 R}{(t+2 R)}
$$

Figure 4 is a plot of $V_{A} /(d V / d y)$ MAX versus $(2 R) /(t+2 R)$, which now approaches a more nearly linear relationship. Inspection of Figure 4 suggests that if one or other of the reduced variables were expressed in a powe $r$ relationship, linearity would be achieved. Therefore the same reduced variables were replotted on $\log -\log$ paper as shown in Figure 5 . Indeed, the initial portion of the $\log -\log$ trace for small values of $t$, which is on the right, is virtually linear, and the trace for large values of $t$ gradually develops curvature. A solid line and a dotted 1 ine are used in Figure 5 to define the linear and curved portions, respectively. 


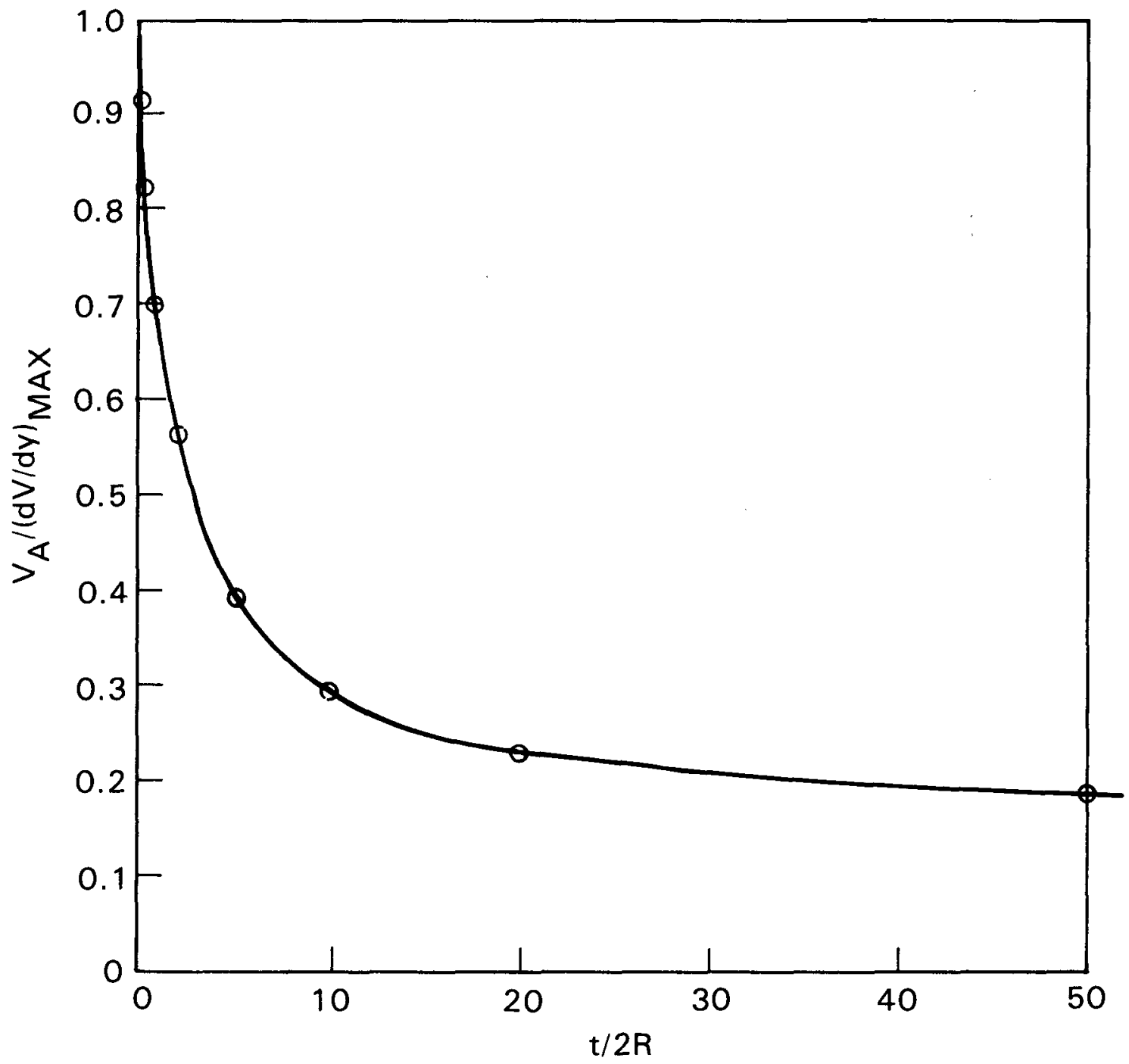

Figure 3. Plot of Data in Table 2

The slope of the linear portion is 0.54 , therefore resulting, for the linear portion, in the following connective relationship:

$$
\mathrm{V}_{\mathrm{A}} /(\mathrm{dV} / \mathrm{dy})_{\mathrm{MAX}}=\left[\frac{2 \mathrm{R}}{(t+2 \mathrm{R})}\right]^{0.54}
$$

Equation 1 can be re-expressed as

$$
v_{A}=(d V / d y)_{\text {MAX }}(2 R)^{0.54}(t+2 R)^{-0.54}
$$




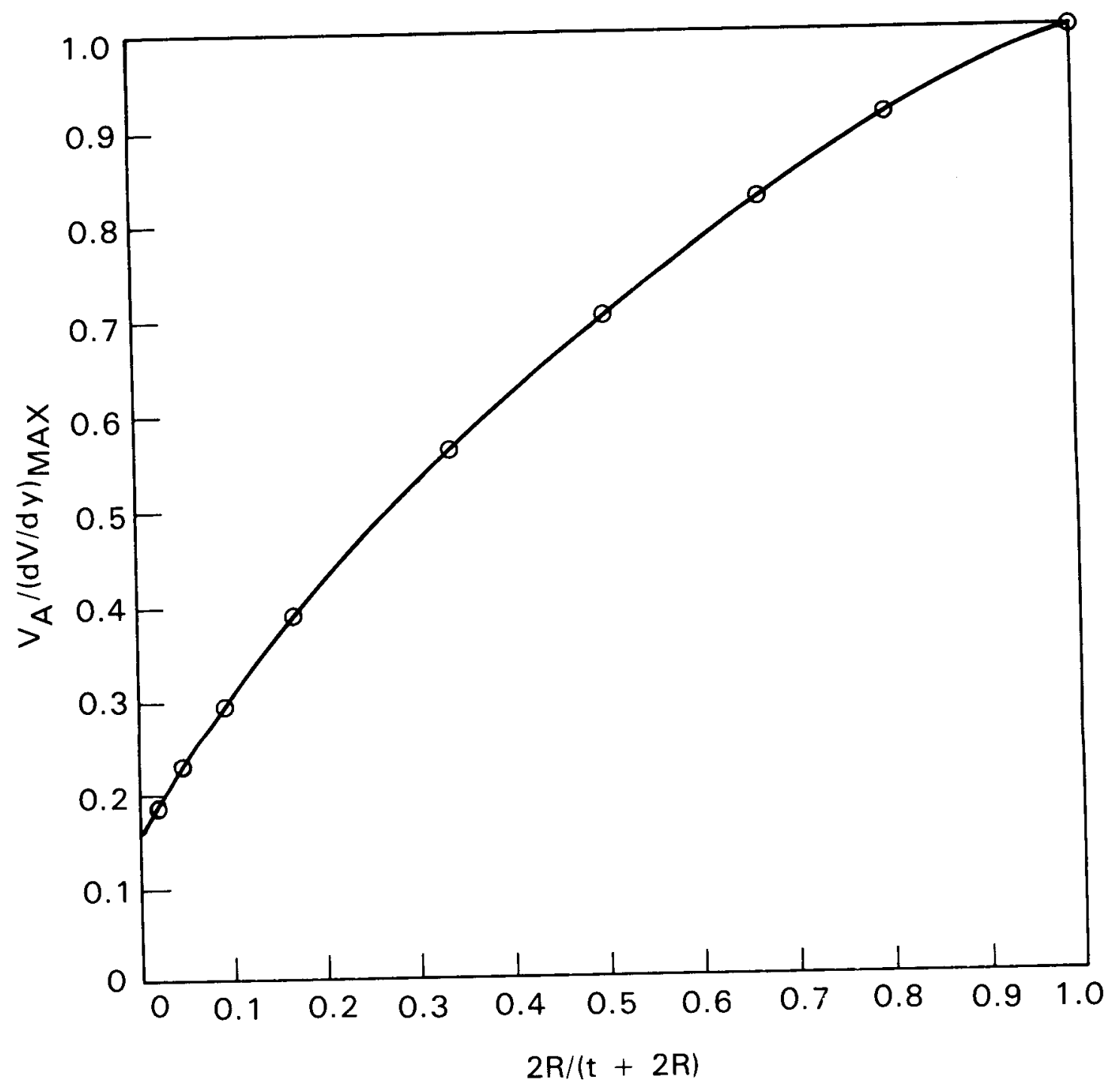

Figure 4. Linear-Linear Plot of Table 2 Data as $V_{A} /(d V / d y)_{M A X}$ Versus the Variable $2 R /(t+2 R)$

and if $K$ is defined as

$$
K=(\mathrm{dV} / \mathrm{dy})_{\operatorname{MAX}}(2 \mathrm{R})^{0.54}
$$

Equation 2 becomes, finally,

$$
v_{A}=K(t+2 R)^{-0.54}
$$




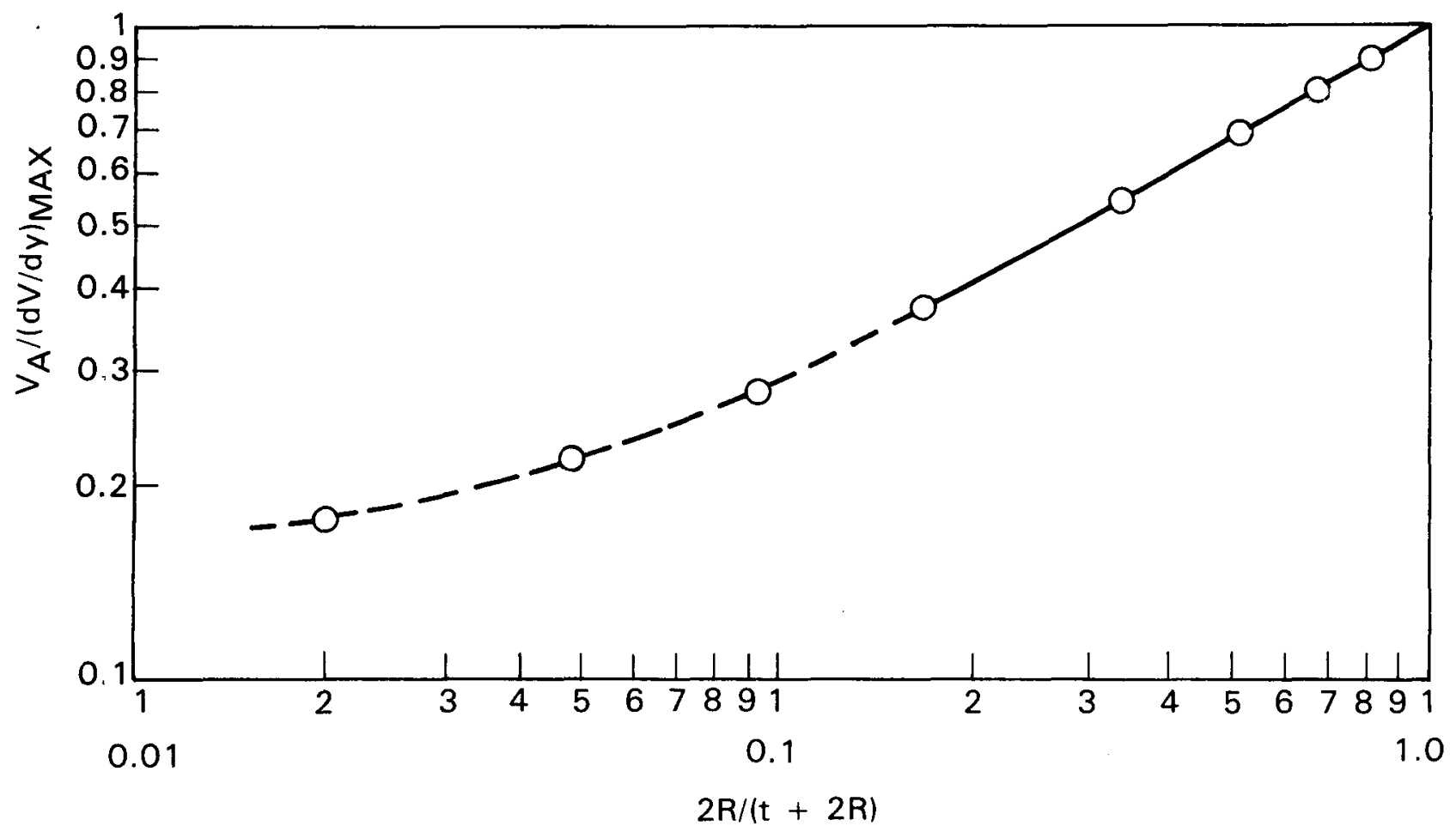

Figure 5. Log-Log Plot of Table 2 Data as $\mathrm{V}_{\mathrm{A}} /(\mathrm{dV} / \mathrm{dy})_{\mathrm{MAX}}$ Versus the Variable $2 R /(t+2 R)$

If the term $2 R$ in Equation 4 is ignored, the form of Equation 4 is strikingly similar to the historically observed empirical square-root relationship between the average breakdown voltage of insulation materials, here being $\mathrm{V}_{\mathrm{A}}$, and insulation thickness $\mathrm{t}$ :

$$
\mathrm{V}_{\mathrm{A}}=\mathrm{K}(\mathrm{t})^{-1 / 2}
$$

This empirical relationship is commented on, or utilized for data correlation, in a diverse cross section of published papers and articles on electrical insulation behavior, and is also described in the appendix of the standard ASTM-D-149-64 (Reference 5) test procedure for measuring the dielectric strength of insulation materials. In general, $\mathrm{V}_{\mathrm{A}}$, the average breakdown voltage, is assigned to be the dielectric strength, and the caveat is that (at least) the experimental test conditions, the environment, material thickness, and electrode geometries must be specified.

Using Equation 5, Figure 6 is a data correlation between the average breakdown voltage $v_{A}$ (dielectric strength) and sample thickness $t$ for polymethyl methacrylate (PMMA), using data values extracted from technical bulletins as remarked in the figure. A least-squares fit of these data with Equation 5 conforms to the empirical expectation.

One explanation for the empirically observed relationship between $v_{A}$ and $t$ appears to be rooted in a material flaw theory, remarks on which are found in published articles on insulation behavior (e.g., Reference 3). The 


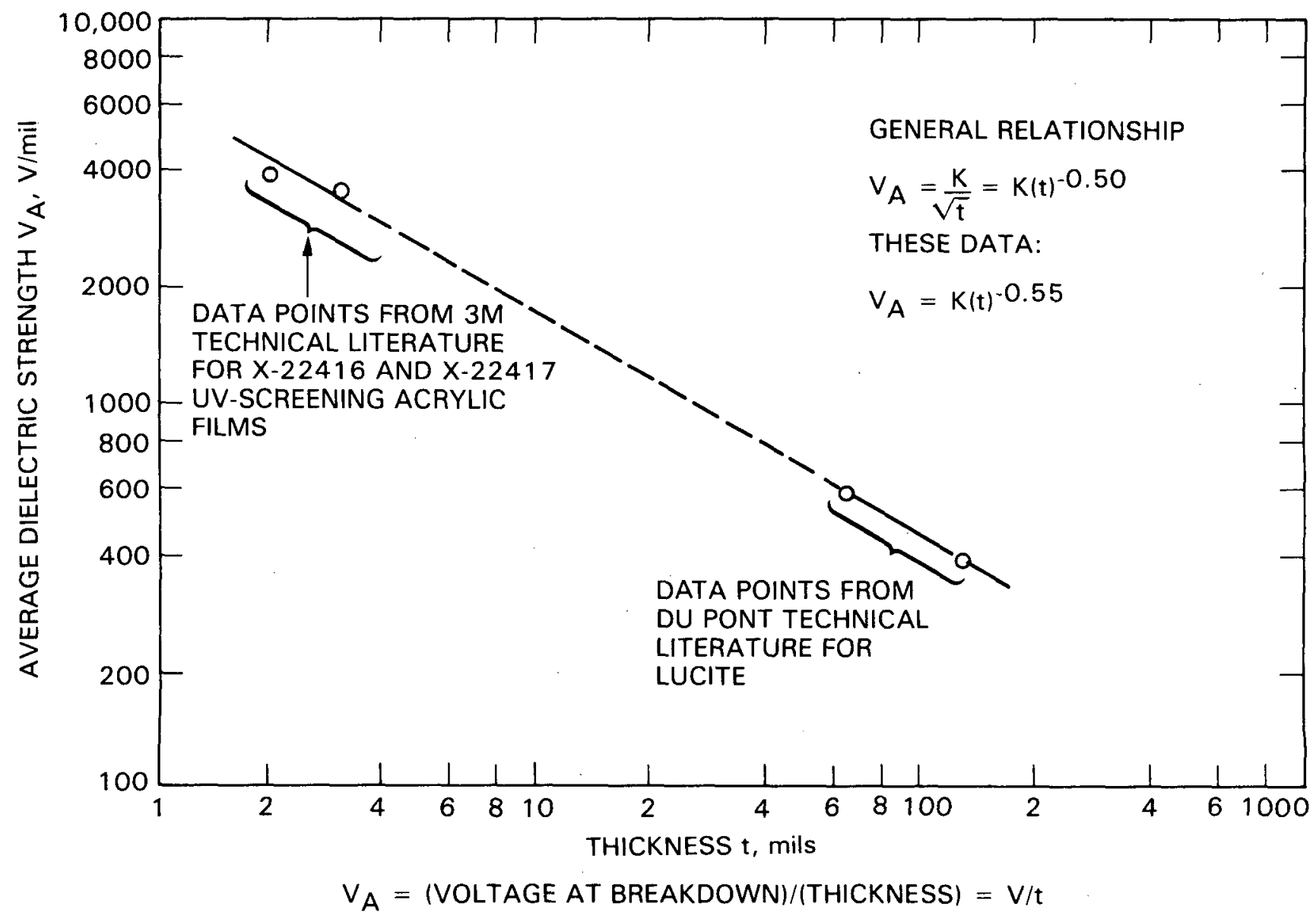

Figure 6. Dielectric Strength of PMMA Acrylic

concept is that material flaws of whatever kind act to cause or contribute to voltage breakdown, and as these flaws are expected to be randomly distributed throughout the bulk of the insulation material, thus statistically more flaws become available in thicker materials, thus reducing the voltage at breakdown (dielectric strength). Conceptually, a flaw-free state occurs for thickness $t$ equal to zero; therefore $V_{A}$ in the limit of $t=0$ would constitute a flaw-free measurement of the intrinsic dielectric strength of insulation materials. Stated another way, this view can support research to seek identification of these troublesome flaws, elimination of which would lead to improvements in insulation materials for electrical service.

However, Equation 4, and therefore Equation 5 if the term $2 \mathrm{R}$ is ignored, was generated on the basis of the electrical field distribution throughout a space of thickness $t$, originating from a curved surface of radius $R$ (which could also be an edge or corner). This is a material-independent situation. 


\section{B. A DIFFERENT VIEW}

It is to be noted for Equations 1, 2, or 4, which are merely different algebraic forms, that when $t$ is equal to zero, then

$$
\mathrm{V}_{\mathrm{A}}=\mathrm{V} / \mathrm{t}=(\mathrm{dV} / \mathrm{dy})_{\mathrm{MAX}}
$$

It is here that the new concept states that (dV/dy) MAX is the intrinsic dielectric strength of insulation materials. The principle is that, as $V$ increases, the material in test will fail when ( $d V / d y)$ on the electrode surface reaches the value of $(d V / d y)$, now considered a material property, and which is associated with a specific insulation material.

Before proceeding further, it is important to determine if the form of Equation 4 is unique to the geometry depicted in Figure 2, or is a general consequence of any electrode geometries and their associated field distributions. Table 3 details two analytical solutions of La Place's field equations for electrode geometries consisting of a needle tip-to-ground plane configuration, and for a needle-tip-to-needle-tip configuration (References 6 and 7 ).

Table 3. Analytical Solutions of La Place's Field Equations for Needle Electrodes

Tip-To-Ground Plane (Reference 6)

$$
\begin{aligned}
(\mathrm{dV} / \mathrm{dy})_{\mathrm{MAX}} & =2 V_{A} t P / \operatorname{Ln}(\mathrm{Q}) \\
\mathrm{P} & =(1+\mathrm{R} / \mathrm{t})^{1 / 2} / \mathrm{R} \\
\mathrm{Q} & =\left[2 t+\mathrm{R}+2 \mathrm{t}^{1 / 2}(\mathrm{t}+\mathrm{R})^{1 / 2}\right] / \mathrm{R}
\end{aligned}
$$

Tip-To-Tip (Reference 7)

$$
(d V / d y)_{\text {MAX }}=\frac{V_{A} t(1+2 R / t)^{1 / 2}}{2 R \tanh ^{-1}[t /(t+2 R)]^{1 / 2}}
$$


Both of these analytical solutions can be series-expanded (Appendix A), and when the first two terms of each of their respective series expansions are algebraically combined, the result is:

$\underline{\text { Tip-To-Tip }}$

$$
V_{A}=(d V / d y)_{\operatorname{MAX}}(3 R)(t+3 R)^{-1}
$$

Tip-To-Ground

$$
\mathrm{V}_{\mathrm{A}}=(\mathrm{dV} / \mathrm{dy})_{\mathrm{MAX}}(\mathrm{R})(t+\mathrm{R})^{-2 / 3}
$$

Equations 7 and 8 , derived from analytical solutions, are identical in form to Equation 2, which was derived from a computer solution of La Place's field equation for the geometry in Figure 2. What is different for Equations 2, 7, and 8 are the integer multiplier of $R$, and the value of the exponent, both of which are being dictated by electrode geometries and pairings. Pairings are the use of two equivalent electrodes as in Equation 7 , or two non-equivalent electrodes as in Equations 2 and 8 . It is convenient to refer to these electrode pairings as "symmetric" or "asymmetric."

In general, for small values of $t$ or large values of $R$, Equations 2, 7, and 8 are of the general form

$$
v_{A}=K(t+a)^{-n}
$$

where $a$ and $n$ are dictated by electrode geometries and pairings, and when $t=0$,

$$
\mathrm{v}_{\mathrm{A}}=\mathrm{K}(\mathrm{a})^{-\mathrm{n}}=(\mathrm{dV} / \mathrm{dy})_{\mathrm{MAX}}
$$

Recently A.S. Pillai and R. Hackam (Reference 8) reported on computergenerated values of the electric field and potential distributions for unequal spheres separated by various gap lengths, and presented their results in tables. Analysis of their tabulated data revealed that, for small gaps, their data also converged to fit the form of Equation 9. This same general convergence at small values of $t$ of solutions to La Place's field equations is found in very early literature dating back to 1924 (Reference 9), 1928 (Reference 10), and 1941 (Reference 11).

Given that Equation 9 is indeed a general convergence solution at small values of $t$ for electrical field distributions, this leads to speculation on 
what must be the natural insulation property of a dielectric for Equation 9 behavior to be reflected in the experimental testing as in Equation 5 for solid dielectrics. The working speculation is that electrical breakdown of an insulator involves two distinct stages, an initiation stage and a propagation stage, and that the driving stress is the voltage gradient (dV/dy). It is further speculated that the stress, i.e., ( $d V / d y)$, required for initiation is greater than the stress required for propagation. This parallels, for example, the mechanical tear behavior of polymers, which have a high initiation stress and a low propagation stress. Now the electrode geometries establish the $(d V / d y)$ relationship throughout the insulator, which for the geometry of Figure 2 has maximum $(d V / d y)$ at the surface of the rounded edge, and minimum $(\mathrm{dV} / \mathrm{dy})$ at the surface of the opposite, flat ground plate. The Spectrolab computer analysis indicates that as the voltage difference between the two electrodes is increased, the level of $(\mathrm{dV} / \mathrm{dy})$ at any insulation location increases in direct proportion; thus the relative ( $\mathrm{dV} / \mathrm{dy}$ ) relationship throughout the insulation is preserved, and only the magnitude increases.

Since the maximum $(\mathrm{dV} / \mathrm{dy})$ is always at the rounded edge for any voltage level, initiation of electrical breakdown in the insulator material will occur when increasing voltage increases the ( $d V / d y)$ level at the curved surface to be equal to the required initiation value of the insulation material. Thereafter, propagation proceeds rapidly through the insulation material, driven by $(\mathrm{dV} / \mathrm{dy})$, until it reaches a location in the insulation material where the level of $(\mathrm{dV} / \mathrm{dy})$ established by electrode geometries is less than the propagation value. At this location, propagation stops.

Two conditions can now occur; the minimum ( $\mathrm{dV} / \mathrm{dy})_{\mathrm{MIN}}$ established by the electrode geometries is either greater than or less than the propagation $(d V / d y)_{\text {PRO }}$ of the insulation material. If greater, i.e., $(d V / d y)_{M I N}>(d V / d y)_{\text {PRO }}$, electrical breakdown will proceed completely through the insulation material. If less, i.e., $(\mathrm{dV} / \mathrm{dy})_{\mathrm{MIN}}<(\mathrm{dV} / \mathrm{dy})_{\text {PRO }}$, electrical breakdown will proceed only partway through the insulation. This often occurs with needle electrodes. This is because the voltage gradients ( $i . e ., d V / d y$ ) are very high near the needle tip, and drop within a short distance into the insulator space to very low values, which, in line with this concept, are lower than ( $\mathrm{dV} / \mathrm{dy}$ ) PRO of the insulator. For non-needle electrodes, such as used for ASTM-D-149 testing, $(\mathrm{dV} / \mathrm{dy})_{M I N}$ is presummed to be greater than ( $\mathrm{dV} / \mathrm{dy}$ ) PRO; thus breakdown proceeds totally through the polymeric insulation material.

In summary, this concept states that an electrical field imposes a mechanical stress on the insulation material, and that mechanical failure is initiated at the site of the highest electrical field intensification, which is, therefore, also the site of highest mechanical stress. In this concept, initiation is considered to occur essentially on the surface of an insulation material, or if the material encloses a conductor, at the interfacial surface between the conductor and the insulation. Therefore, it might be expected that the environmental and material properties at the surface adjacent to the site of high field intensity are more critical than average bulk material properties, or environments some distance removed.

It is also well known that voltage breakdown of insulation materials is associated with measurable detection of electrical current. Recently Dickenson et al (Reference 12) have reported that mechanical fracture of polymeric materials results in a release of charged particles and electrons at 
the fractured interface. Electrodes with a potential difference are positioned on opposite sides of the test material, and as the electrical-fieldinduced mechanical stresses initiate mechanical fracture, the fracturareleased charge particles and electrons could be attracted to these electrodes and constitute a detectable current flow. In other words, current flow and detection are consequences of material fracture and breakdown, as opposed to being a cause of the material failure by electrode injection of electrons.

Dickenson et al (Reference 13) observed that as the mechanical stress on a material is increased, initiation of stress-induced electron emission in the material bulk begins at stresses substantially below the ultimate failure stress. Thereafter, electron emission accelerates with increasing mechanical stress. This could be the origin of the discharge-inception-voltage in electrical stress testing, the voltage associated with incipient current detection, but such voltage is still substantially below the ultimate voltage measured at total material breakdown. A mechanical stress design limit called the "proportional limit" is described below, and this may be the mechanical stress level caused by electrical field intensification associated with the dischargeinception-voltage. It is also postulated below that the proportional 1 imit is the threshold voltage recognized as the upper voltage limit for safe insulation design.

\section{C. (dV/dy) AT VOLTAGE BREAKDOWN}

FSA testing related to dielectric strength and voltage breakdown measurements of encapsulation pottant materials (Table 1) is just beginning, and only one preliminary set of voltage breakdown data has been measured for the EVA pottant. At the time of this preliminary test, it was convenient to use a symmetric pairing of electrodes, which was not dictated by any of the concepts or theories being described in this article. It turned out to be a fortuitous choice. The test results measured on three thicknesses of EVA film are given in Table 4, along with the calculated average dielectric strength $\mathrm{V}_{\mathrm{A}}$.

Using the $V_{A}$ and $t$ data given in Table 4, Equation 9 was solved for $K$, $a$, and $n$ by a least-squares technique to yield the following:

$$
\mathrm{V}_{\mathrm{A}}=19173(t+3.74)^{-0.96}
$$

and therefore for $t=0$

$$
(\mathrm{dV} / \mathrm{dy})_{\mathrm{MAX}}=\mathrm{K}(\mathrm{a})^{-\mathrm{n}}=5404 \text { volts } / \mathrm{mil}
$$


Table 4. Average Breakdown Voltage of Ethylene Vinyl Acetate for Three Film Thicknesses

$\begin{array}{clc} & \text { Average } & \text { Average } \\ \text { Thickness } & \text { ac Breakdown } & \text { Dielectric Strength } \\ \mathrm{t}, \mathrm{mils} & \text { Voltage, } \mathrm{kV} & \mathrm{V}_{\mathrm{A}}=\mathrm{V} / \mathrm{t}, \mathrm{kV} / \mathrm{mil}\end{array}$
4.7
11.7
2.49
6.0
13.0
2.17
15.7
17.6
1.12

In light of the concept being described here, it is tempting to assign the value of $(\mathrm{dV} / \mathrm{dy})_{\text {MAX }}=5404 \mathrm{volts} / \mathrm{mil}$ as the intrinsic dielectric strength of EVA, and to state that whenever this electrical field intensity is reached on an electrode surface in contact with EVA, the EVA material will experience voltage breakdown. Figure 7 is a log-log plot of $v_{A}$ versus the thickness term $(t+3.74)$. This is similar to the historically empirical data correlation technique of plotting $V_{A}$ versus thickness $t$ on 1 og- 1 og paper, except that here the term a is included along with $t$ in the abscissa. Again $V_{A}$ decreases with increasing values of $t$, not because of any material characteristic, but because of the behavior of the electrical field distribution associated with increasing the gap thickness between electrodes (which happens here to be filled with EVA).

It is to be recalled that this EVA test was fortuitously carried out with symmetric electrodes, and that in Equation 11 the value of the exponent $n$ is 0.96 , or very nearly 1 . This may be compared with Equation 7 , which is the convergence solution for small values of $t$ for symmetric tip-to-tip electrodes, which happens to have an exponent $n$ of 1 . If similarities continue, then the effective radius-of-curvature $R$ associated with this voltage breakdown is found in the a value, by dividing by 3 . Hence, $R$ is equal to $3.74 / 3=1.24 \mathrm{mils}$.

In a 1955 paper (Reference 6), Mason reported experimental results of the measurement of the average dielectric strength $v_{A}$ of low-density polyethylene as a function of sample thickness. For his test, Mason used an asymmetric electrode pairing, with the ground electrode being a flat plane. Using his published $v_{A}$ and $t$ data for polyethylene, Equation 9 was solved by a least-squares technique for $k, a$, and $n$, yielding the following result:

$$
V_{A}=8337(t+1.20)^{-0.67}
$$

and for $t=0$ 


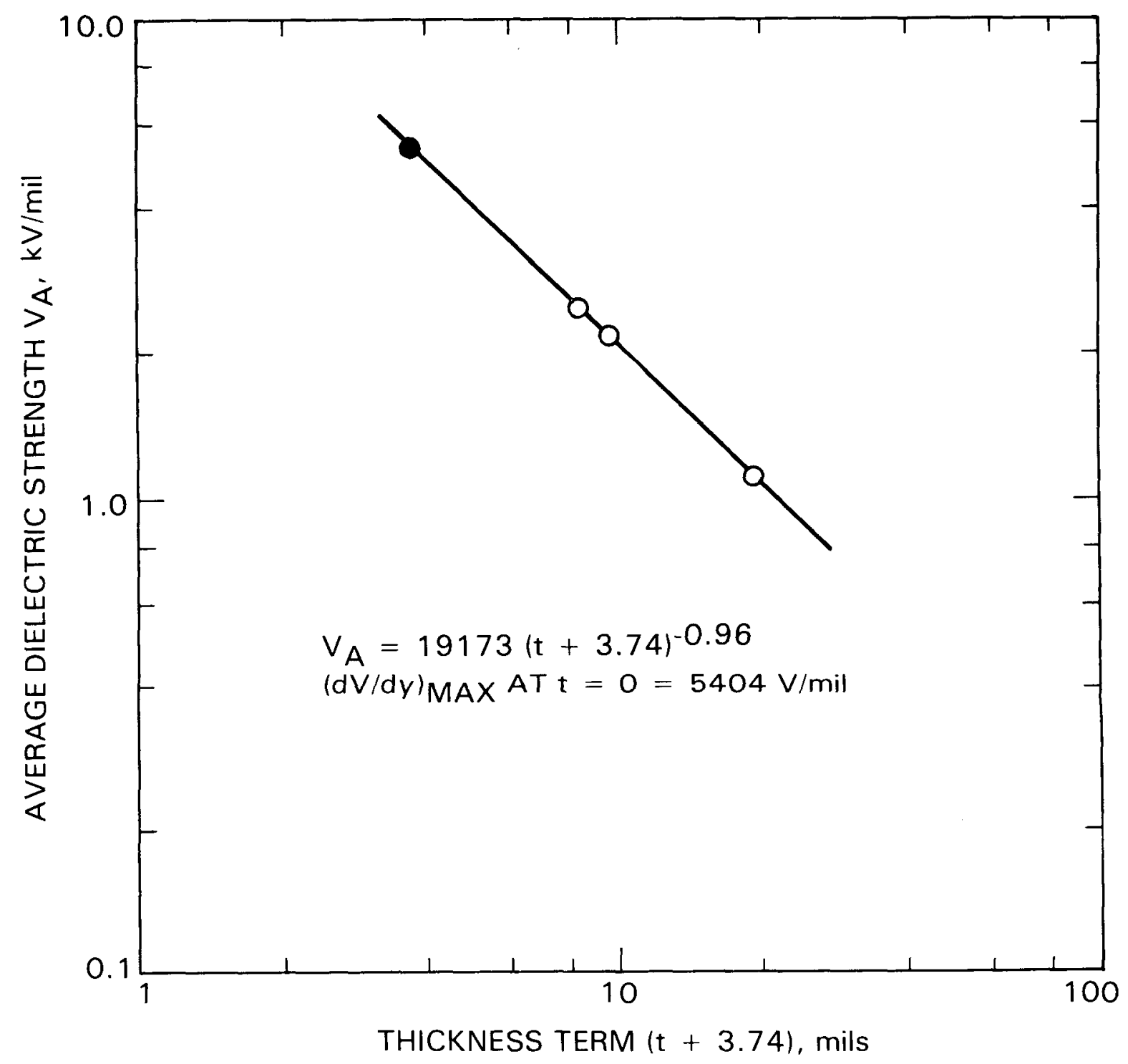

Figure 7. Dielectric Strength of Ethylene Vinyl Acetate

$$
\mathrm{V}_{\mathrm{A}}=(\mathrm{dV} / \mathrm{dy})_{\operatorname{MAX}}=7378 \mathrm{volts} / \mathrm{mil}
$$

His data, plotted as $\mathrm{V}_{\mathrm{A}}$ versus the term $(t+1.20)$, are shown in Figure 8 .

Note the striking similarity of Equation 13 for Mason's polyethylene data measured with asymmetric electrodes and Equation 8 , the convergence solution for the asymmetric tip-to-ground electrode configuration. Not only are the values of the exponent $n$ essentially the same, but also, for Mason's data, the value of $a$, which is equal to $R$ in Equation 8 , is the same value of $R$ derived from the EVA data using symetric electrodes. 


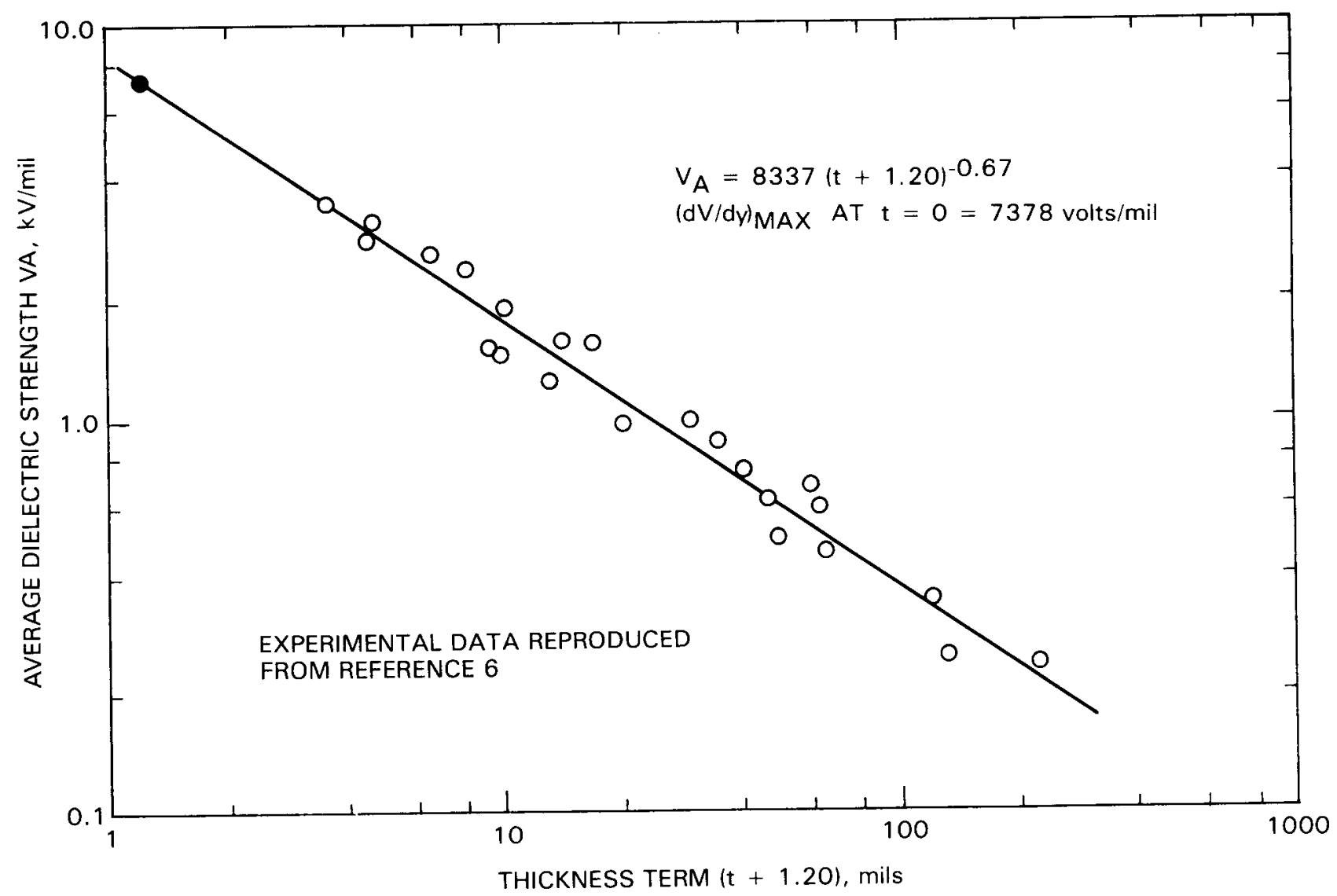

Figure 8. Dielectric Strength of Polyethylene

It is tempting to assign the value of $(\mathrm{dV} / \mathrm{dy})_{\operatorname{MAX}}=7378 \mathrm{volts} / \mathrm{mil}$ as the intrinsic dielectric strength of polyethylene, and more will be said about this below, in combination with the "proportional 1imit," when the discussion centers on buried polyethylene-insulated high voltage cables.

Last, the data for polymethyl methacrylate (PMMA) shown in Figure 6 , which was extracted from separate technical data bulletins, was also fit to Equation 9 by a least-squares technique, yielding the following:

$$
v_{A}=8009(t+0.87)^{-0.63}
$$

and for $t=0$

$$
\mathrm{V}_{\mathrm{A}}=(\mathrm{dV} / \mathrm{dy})_{\mathrm{MAX}}=8740 \mathrm{volts} / \mathrm{mil}
$$

The separate technical bulletins reported that the voltage breakdown testing was carried out with asymmetric electrodes. With recognized possibilities of some inaccuracy that may result from merging separate experiment data, Equation 15 reflects the behavior now expected for asymetric electrodes. 
Comparing the three materials, EVA, polyethylene, and PMMA, they are a soft elastomer, a semi-hard thermoplastic, and a rigid plastic, respectively. It is noted for each that their respective value of $(\mathrm{dV} / \mathrm{dy})_{\mathrm{MAX}}$ also increases in the same order. In itself this is not a new observation, as the recognition of a relationship between material hardness and average dielectric strength can be found in early literature on electrical insulation studies (e.g., Whitehead, Reference 13). Thus if $(\mathrm{dV} / \mathrm{dy})_{\mathrm{MAX}}$ is the intrinsic dielectric strength, the observations reported here agree with historical observations.

It is interesting to note that for the three materials, the range of $(\mathrm{dV} / \mathrm{dy})$ values from 5404 to 8740 volts/mil is surprisingly narrow, considering that the materials range from a soft elastomer below its glass transition temperature $\left(\mathrm{T}_{\mathrm{g}}\right)$, to a rigid plastic above its $\mathrm{T}_{\mathrm{g}}$. In 1976, Swanson et al (Reference 14) reported dielectric strength measurements made on a wide variety of polymeric materials, ranging from soft, to semi-hard, to rigid. They concluded that $\mathrm{T}_{\mathrm{g}}$ had only a slight effect on dielectric strength values.

D. THE EFFECTIVE RADIUS OF CURVATURE ( $R$ )

The voltage breakdown data reported above were obtained using symmetric and asymmetric electrodes contacting the opposite surfaces of a test material, as shown in Figure 9. Using those data and Equation 9, an effective radius of curvature $R$ of nominal value $1.2 \mathrm{mils}$ was calculated for the EVA and polyethylene data, and a nominal $R$ value of $0.87 \mathrm{mils}$ was calculated for the PMMA data. This latter value may be inaccurate due to the use of merged data from different technical data sources.

Nevertheless, there appears to be no immediate correlation between these values of $R$ and those quoted, for example in ASTM-D-149-64, for the radii of standard test electrodes. It is interesting to speculate that perhaps there should be no correlation at all. This author witnessed experimental ac voltage breakdown testing, and observed that the electrical arc at the moment of breakdown leaps from the electrode surface, through air, to the sample. Apparently the arc is seeking a site of minimum material thickness in the immediate vicinity of the electrode, but it is the "through the air" that may be dictating this effective radius of curvature.

Along these lines, Mason reported data (Reference 6) on measurement of the average voltage-at-breakdown $V_{A}$ of polyethylene by needle electrodes inserted into the polyethylene test material. The needle electrodes had a range of tip radii from about 1.5 to 40 micrometers $(0.06$ to $1.57 \mathrm{mils})$, and his experimental results are shown in Figure 10, from his Figure $7(G)$ in Reference 6 . The average voltage-at-breakdown decreased as the radii of the needle tips decreased from 40 to 10 micrometers, and thereafter essentially no further reduction in voltage-at-breakdown occurred with continuing decreases in the radii of the needle tips. This follows from inspection of his data line in Figure 10, but he also has two data points closer to 20 micrometers, which appear to be in the asymptotic minimum region for the average breakdown voltage. 

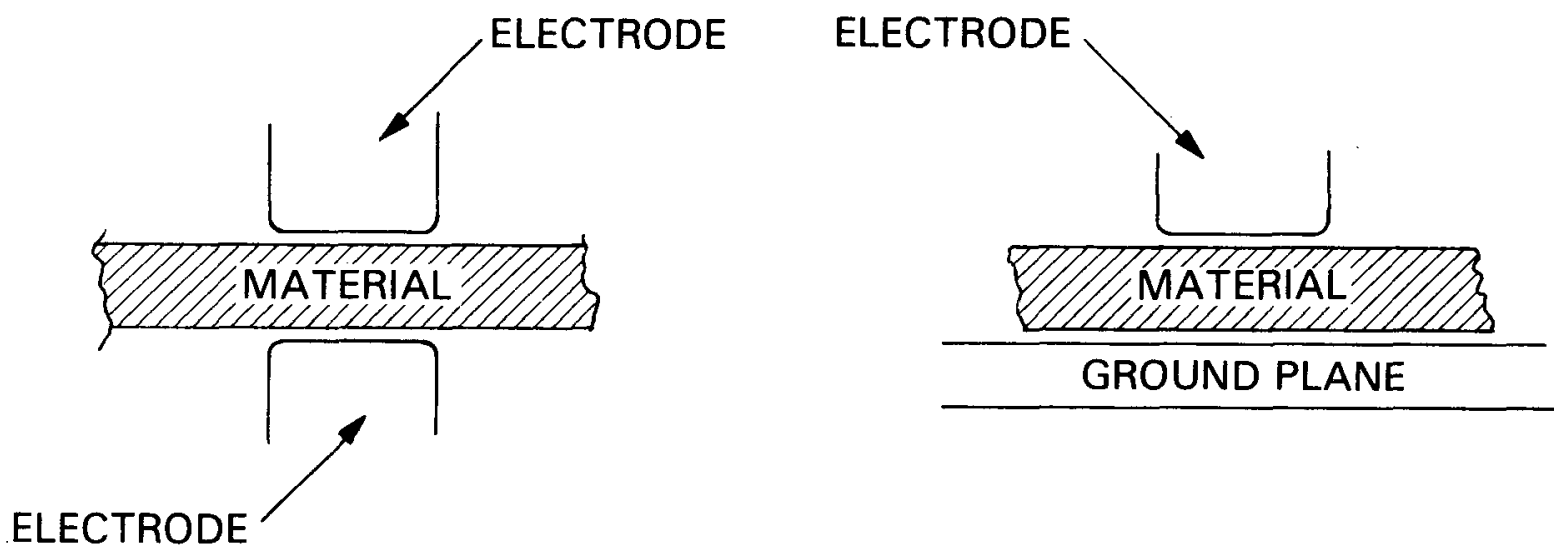

Figure 9. Symmetric and Asymmetric Electrode Pairings

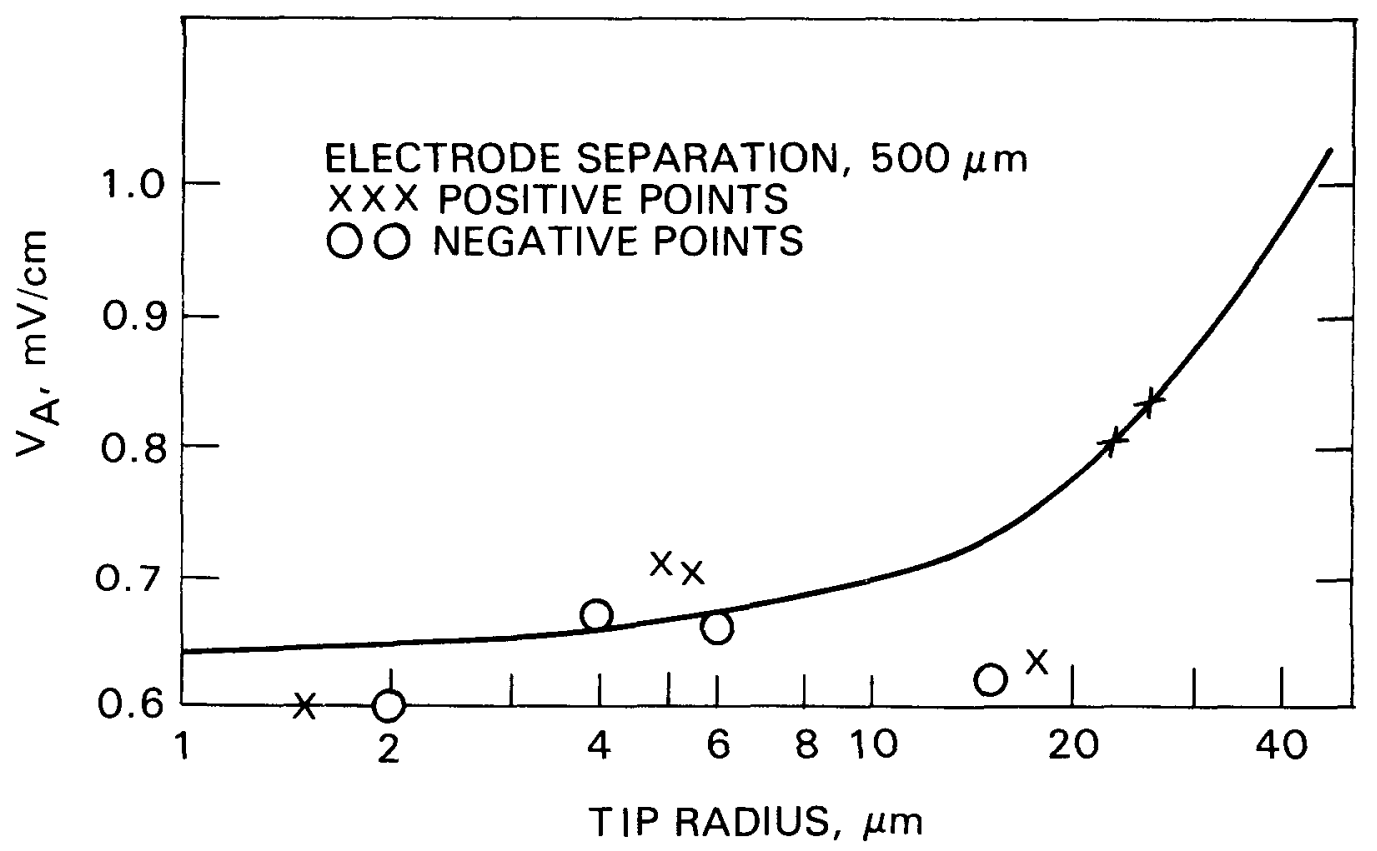

Figure 10. Dependence of Average Breakdown Voltage $\mathrm{V}_{\mathrm{A}}$ of Embedded Needle Electrodes at $60^{\circ} \mathrm{C}$ (Figure $7 \mathrm{~b}$ in Reference 6)

What his data imply is that electrical field intensification peaked to a limit value when tip radii became less than 10 to 20 micrometers $\approx 0.4$ to $0.8 \mathrm{mil}$ ), no matter how much smaller the tip radii. It is interesting to observe that these tip radii are in the order of magnitude of those generated by the least-squares fit of Equation 9 with the voltage breakdown data described above. 
From the foregoing, there appears to be a hint that some natural but not yet clearly understood law of physics is regulating this effective radius of curvature to be somewhere in the nominal range of perhaps 0.4 to $1.2 \mathrm{mils}$. If this is accepted, even without current understanding, having knowledge of that value of $R$ that can be associated with the edges, corners, nicks, and surface dents of electrically conductive devices, as well as a value of ( $\mathrm{dV} / \mathrm{dy})_{\mathrm{MAX}}$ that can be associated with the insulation material, and a value of $n$ determined by symmetric or asymetric device configurations, new vistas are opened on electrical stress failure analysis, and on safe electrical stress design.

The 1976 article by Swanson et al referred to above (Reference 14) reported a value of $742 \mathrm{volts} / \mathrm{mil}$ as the average dielectric strength $\left(\mathrm{V}_{\mathrm{A}}\right)$ for low-density polyethylene. The measurement was made on a 55-mil-thick specimen, using two $1 / 2$-inch-diameter stainless steel balls as electrodes. This electrode pairing is symmetrical. Using a value of $R=1.20 \mathrm{mils}$, and the symmetrical tip-to-tip equation given in Table 3 , a value of $(\mathrm{dV} / \mathrm{dy})_{\mathrm{MAX}}$ $=7653$ volts/mil can be calculated as the intrinsic dielectric strength of low-density polyethylene, in virtual agreement with the value calculated using Mason's 1955 data.

There remains, however, an additional consideration. The value of $(\mathrm{dV} / \mathrm{dy})_{\mathrm{MAX}}$ as herein employed is identified with ultimate failure, identically as the ultimate tensile stress in mechanical testing. Mechanical engineers do not design load-carrying structures to the limit of the ultimate tensile stress of the construction materials, but to a much lower value that is typically less than the material's yield stress. If indeed an electrical field imposes a mechanical stress on electrical insulation materials, then mechanical property considerations may provide a clue to the safe engineering design limits for insulation materials.

\section{E. THE PROPORTIONAL LIMIT}

Figure $11(a)$ is a conventional linear plot of a uniaxially measured stress-strain curve, here illustrated for Mylar polyester film (E.I. Du Pont). The stress is calculated as the force causing extension divided by the initial cross-sectional area $A_{0}$ of the test specimen. This conventional plotting format reveals an initial near-linear relationship between stress and strain, followed by departure from linear behavior at a yield point, and then ductile behavior to the ultimate stress at failure. Since the cross-sectional area decreases with increasing extension, Figure 11(a) does not reflect the true stress, which is the load divided by the actual cross-sectional area at any extension of the test specimen.

Figure $11(b)$ is a replot of the same load-extension data on log- $10 \mathrm{~g}$ coordinates, as true stress versus strain. Although there are similarities with Figure 11(a), it is significant that the stress at departure from initial linearity is not at the conventionally accepted yield point. The actual stress at departure in Figure 11 (b) is called the "proportional limit," and typically is a value about $60 \%$ of yield. For Mylar, the "proportional limit" is about $8,500 \mathrm{lb} / \mathrm{in} .^{2}$ (Reference 15), as compared to its yield stress of near 13,500 1b/in. ${ }^{2}$, which can be extracted from Figure $11(a)$. 

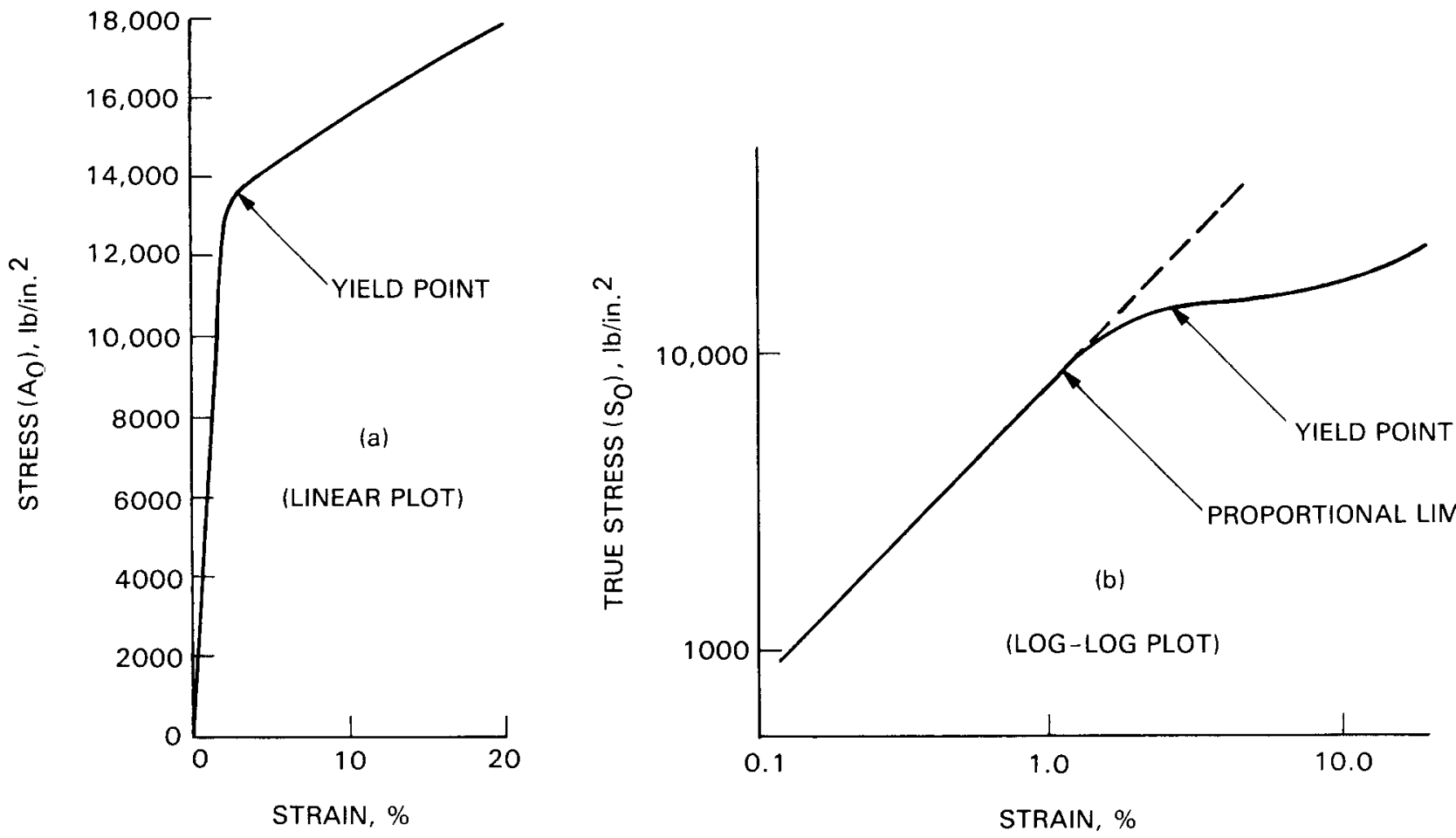

MATERIAL: MYLAR "A"

Figure 11. Comparative Stress/Strain Plots

The significance of the "proportional limit," again illustrated with Mylar material, is shown in Figure 12. Figure $12(\mathrm{a})$ is a plot of the flexural fatigue properties of Mylar, plotted as number of cycles-to-failure versus the peak stress amplitude. The fatigue-endurance limit is that stress level above which an abrupt decrease in cycle lifetime occurs. For Mylar, this occurs at $8500 \mathrm{lb} / \mathrm{in} .^{2}$, which is also its proportional limit.

Mylar, as are many engineering plastic materials (Reference 16), is susceptible to environmental-stress cracking, a phenomenon wherein life-under-stress is reduced dramatically when the material is exposed to certain gases or liquids, which are specific to the stressed material. Mylar is highly susceptible to environmental-stress cracking when stressed in the presence of methyl ethyl ketone (MEK) solvent (Reference 15). Figure 12(b) is a plot of Mylar lifetime when simultaneously stressed and exposed to MEK. Note that the susceptibility to environmental-stress cracking vanishes for stress levels below the "proportional limit"; that is, the solid data line merges asymptotically with the dotted line.

The proportional limit is the upper design limit for mechanical service. It is the stress level at which material behavior departs from its elastic, Hookian behavior, to ductile characteristics. It can be viewed as the beginning point for mechanical service problems, however they may manifest 
(a)

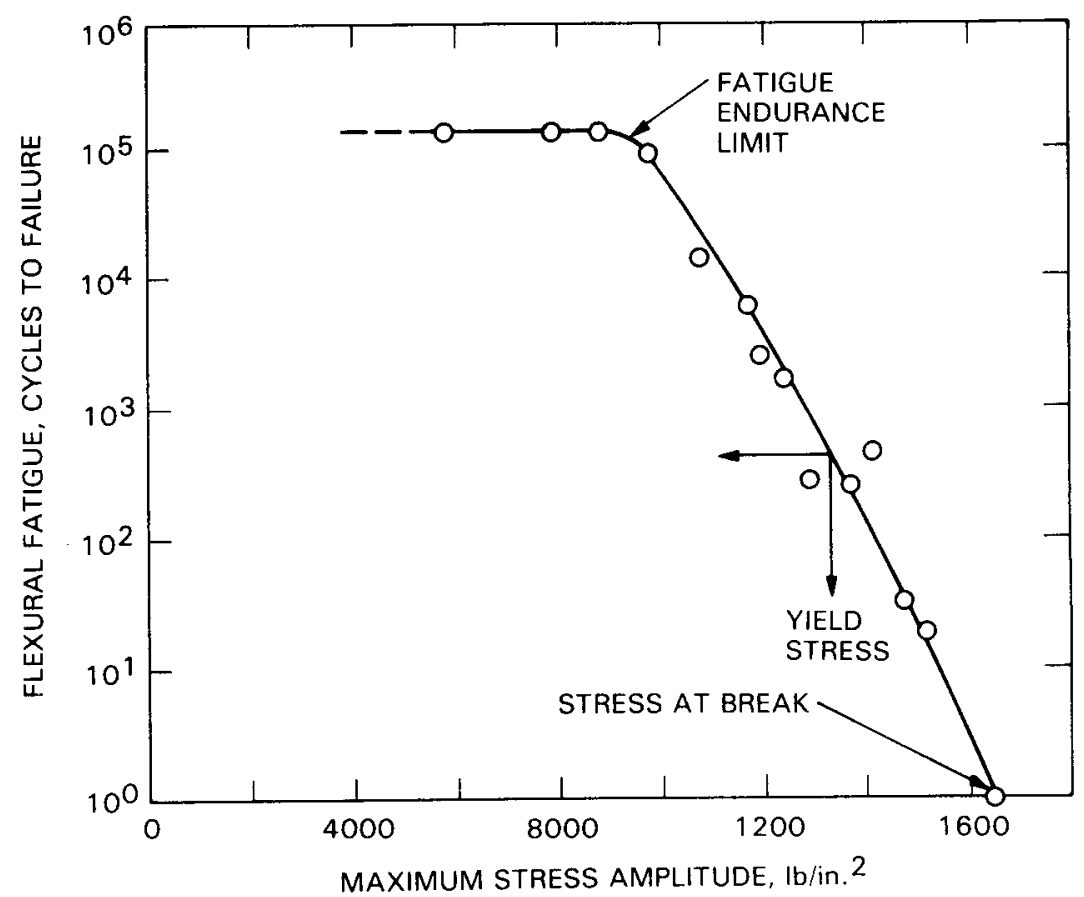

(b)

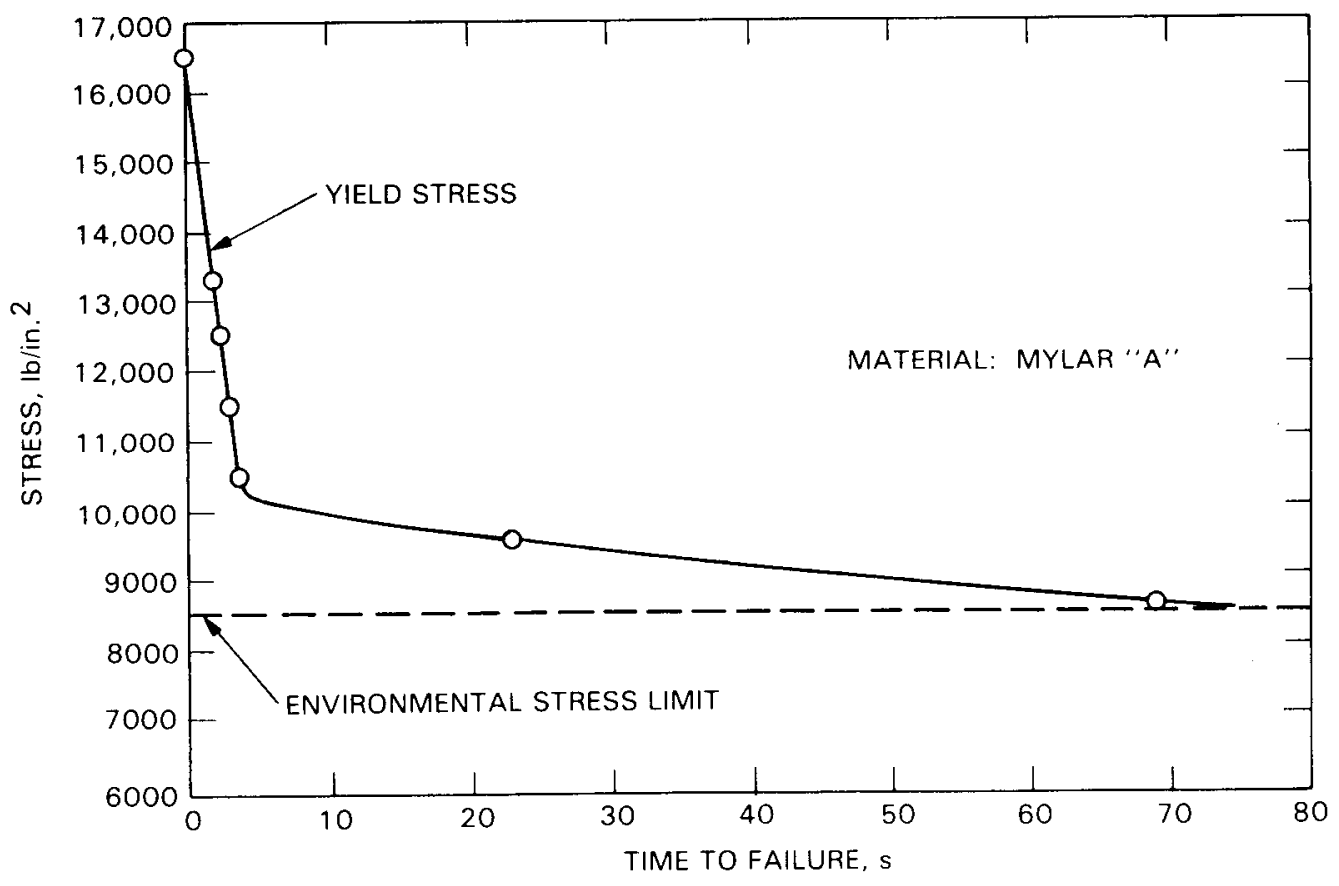

ENVIRONMENTAL STRESS CRACKING

Figure 12. Significance of the Proportional Limit (Proportional Limit = Fatigue Endurance Limit $=$ Environmental Stress Limit) 
themselves. Service stress levels in the region between the proportional himit and ultimate stress can lead to voids, cracks, premature failures, and time-dependent losses in performance.

If indeed electrical fields impose a mechanical stress on electrical insulation materials, then the upper limit of (dv/dy) for electrical insulation design could be regarded as that value of ( $d v / d y$ ) proportionated downward from knowledge of $(\mathrm{dV} / \mathrm{dy})_{\mathrm{MAX}}$ at voltage breakdown, and the mechanical property values of ultimate tensile stress and proportional limit. With this, we can now proceed to offer a possible explanation for polyethylene insulation failures in buried high-voltage cables, and a possible explanation of the origin of both electrical trees and water trees.

\section{F. POLYETHYLENE-INSUlated CABLES}

\section{Orientation}

Using Mason's published data for polyethylene, a value of $(\mathrm{dV} / \mathrm{dy})_{\mathrm{MAX}}=7378 \mathrm{volts} / \mathrm{mi} 1$ was calculated above for the material's intrinsic dielectric strength at voltage breakdown. This value is in sharp contrast with values at or in excess of 20,000 volts/mil, reported as the intrinsic dielectric strength of polyethylene in literature articles dating back to the 1940s (References 17, 18, 19, 20). One article by Austen (Reference 20) reported on measurements of the dielectric strength of oriented paraffin waxes, in directions parallel with and perpendicular to the orientation axis. Austen reported that the dielectric strengths were significantly higher when measured in the direction perpendicular to the orientation axis, as compared with those measured parallel with the orientation axis.

This clue led to the strong suspicion that the polyethylene samples, on which the early dielectric testing was being performed, had become highly oriented as a consequence of the method of sample preparation then in use. Further, the measurements were then made in the direction perpendicular to the orientation axis, which would tend to yield the highest values for dielectric strength. Figure 13 is adapted from Figures 1 and 2 of Reference 17, illustrating recessing devices used to prepare test specimens.

The approach was to position a test specimen between a flat base plate and a ball or mandrel having a large radius of curvature. The base plate was then heated above the softening point of the test specimen, and then the ball or mandrel was pressed into the sample to generate a large indented recess. When cooled, the recess was filled with an electrode material, which by geometry acquired a large radius of curvature. Next, voltage was applied until breakdown, which occurred at the thinnest point in the sample, typically at the bottom of the recess.

Two situations then may develop. First, the sample could become oriented by this method of preparation, and the test proceeds to measure the voltage-at-breakdown in the direction perpendicular to the orientation. 

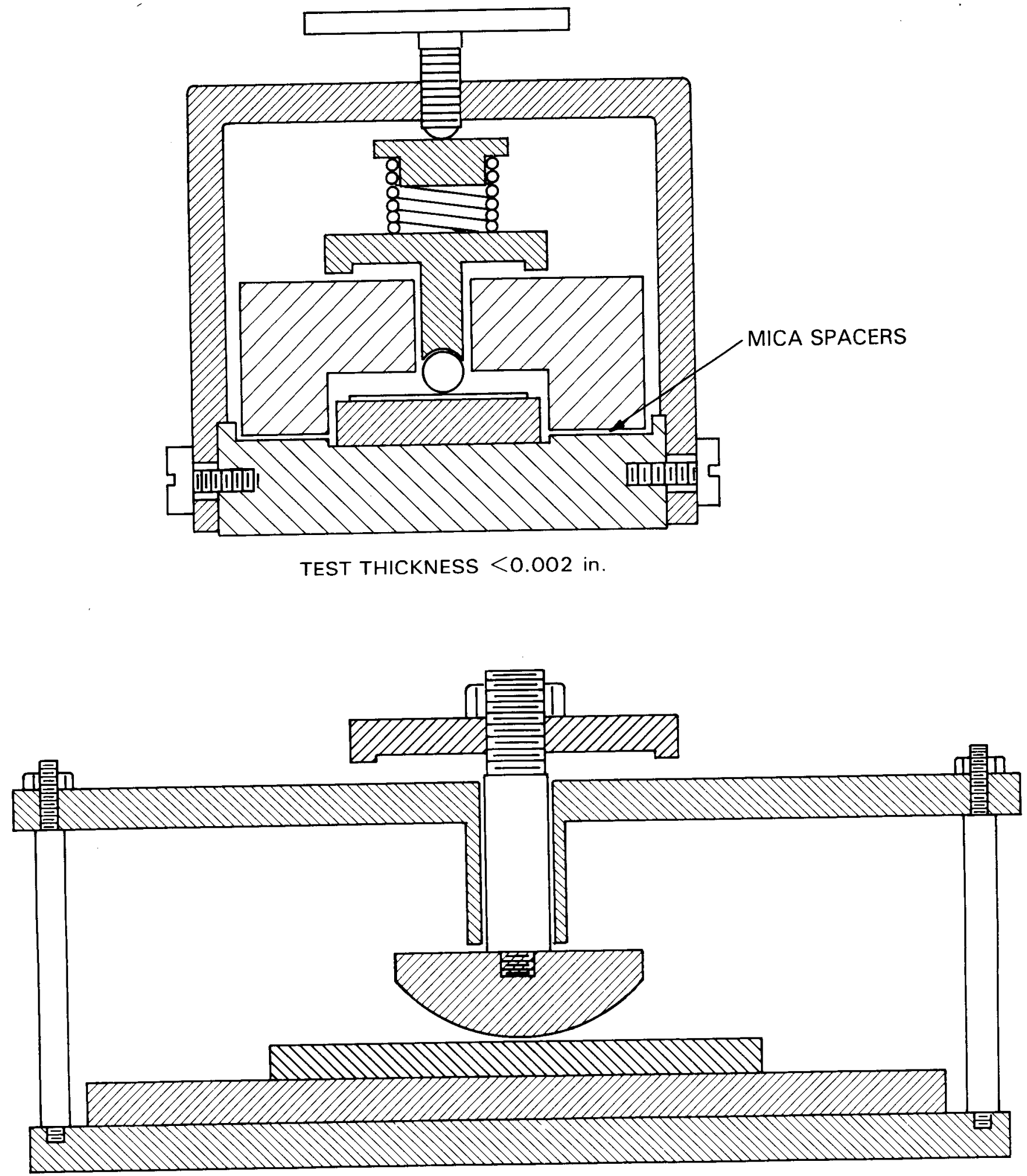

TEST THICKNESS >0.002 in.

Figure 13. Devices Used by Researchers Before 1950 to Prepare Recessed Test Specimens for Electrical-Property Testing (Figures 1 and 2 in Reference 17) 
Second, the electrode in the recess has a large radius of curvature, and under that condition $V_{A}$ is essentially $(d V / d y)$, that is

$$
\mathrm{v}_{\mathrm{A}}=\mathrm{V} / \mathrm{t}=(\mathrm{dV} / \mathrm{dy})
$$

Indeed, it was practice with the recessed-specimen technique to measure the voltage-at-breakdown $V$ as a function of sample thickness $t$, which, because of large $R$, resulted in a linear relationship. Figure 14, adapted from Figure 7 of Reference 17, is typical of the measured relationship between $V$ and $t$ for polyethylene, having a slope that is approximately $20,000 \mathrm{volts} / \mathrm{mi} 1$.

By the very nature of the recessed technique, the test results are an intrinsic dielectric strength in accordance with the concept described here. What apparently could be different between data measured on recessed specimens

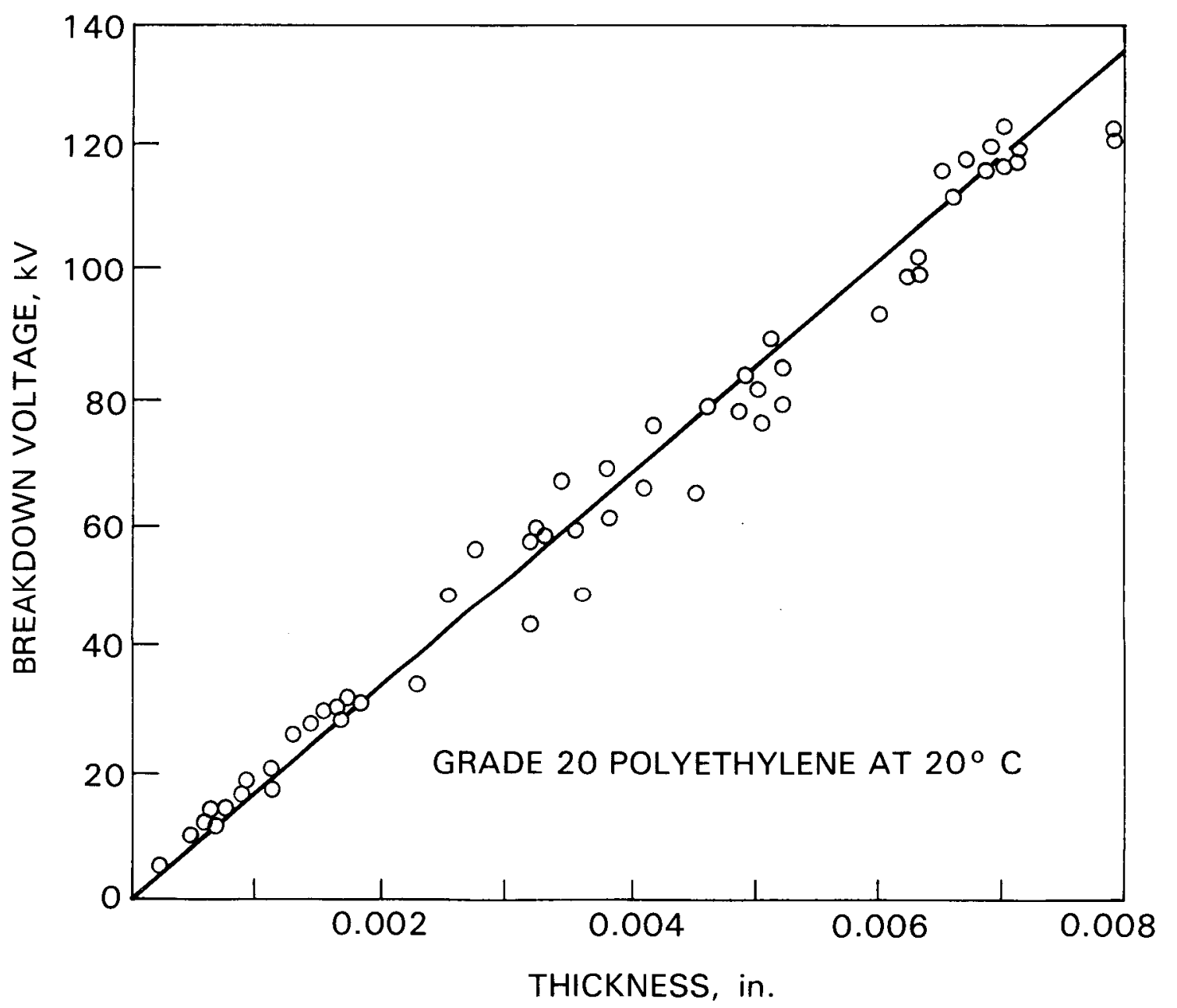

Figure 14. Representative Illustration of the Linear Relationship Between Breakdown Voltage and Sample Thickness, Using Recessed Specimens (After Figure 7, Reference 17) 
in the 1940 s and those of Mason reported in 1955 is orientation effects. Mason made his measurements using contact electrodes as shown in Figure 9, without use of any recessing; therefore, it can be presumed that he tested unoriented, isotropic polyethylene resulting in a value of ( $\mathrm{dV} / \mathrm{dy})_{\mathrm{MAX}}=7378$ volts/mil. This same test approach was used by Swanson et al (Reference 19). By taking the ratio $=(20,000 / 7378)$, it would appear that the recessed polyethylene specimens were being oriented about three times in the thinnest portion of the recess, assuming a linear relationship between orientation factor and dielectric strength increases. This level of orientation is easily accommodated by ductile polymers (for example, commercial Mylar "A" $\mathrm{film}$ is oriented three times in both its length and width directions) (Reference 21), and most polymeric fibers are easily oriented to higher orders

(Reference 22). Since the polyethylene insulation used on a high-voltage cable is extruded uniaxially, similarly as a polymer fiber, its level of orientation aligned with the core might easily exceed three times. Therefore, as manufactured, it would be expected to have an artificially high, orientation-induced dielectric strength in the direction perpendicular to the cable axis.

\section{Proportional Limit}

Table 5 is a tabulation of properties of polyethylene resins, reproduced from Reference 23. For the three polyethylene materials having the highest molecular weight, D-100, D-130, and D-145, the average tensile strength (ultimate strength at failure) is $30601 \mathrm{~b} / \mathrm{in.}{ }^{2}$, and the average yield strength is $1750 \mathrm{lb} / \mathrm{in.}$. Since the proportional limit is approximately $60 \%$ of yield, a value of $1050 \mathrm{lb} / \mathrm{in.}{ }^{2}$ is therefore estimated as the proportional limit for polyethylene. This corresponds to $35 \%$ of the ultimate strength $(100 \times 1050 / 3060)$. Invoking a linear relationship between intrinsic dielectric strength properties and mechanical properties, and using the isotropic dielectric strength at failure, $(\mathrm{dV} / \mathrm{dy})_{\mathrm{MAX}}=7378 \mathrm{volts} / \mathrm{mil}$, it is estimated for polyethylene that its intrinsic dielectric strength associated with the proportional limit is $0.35 \times 7378=2582$ volts $/ \mathrm{mil}$. Stated another way, the threshold voltage of polyethlene for long-1ife service would be about $35 \%$ of the initially measured, short-time voltage at breakdown, if experimentally the same electrodes and sample thickness were consistently employed.

\section{Effect of Water}

Figure 15 illustrates the effect of water on reducing the dielectric strength of Mylar. This figure is reproduced from Du Pont Technical Bulletin M-4D, which provides technical data on the electrical properties of Mylar film material. Analysis of the data in Figure 10 indicates that about a $15 \%$ reduction in dielectric strength occurs upon going from $20 \% \mathrm{RH}$ to $80 \% \mathrm{RH}$. If 1 inearity is assumed, this same reduction would be expected upon going from $40 \% \mathrm{RH}$ to $100 \% \mathrm{RH}$, where $40 \% \mathrm{RH}$ would be a typical room humidity in which dielectric testing is carried out, and $100 \% \mathrm{RH}$ would be the environment of a buried cable in moist soil. It will be assumed that the polyethylene insulation in a buried cable experiences a $15 \%$ reduction in dielectric strength properties, compared with those found in laboratory testing. 
Table 5. Properties of Polyethylene Resins (Adapted from Table LXXXI, Reference 23)

\begin{tabular}{|c|c|c|c|c|c|c|c|c|}
\hline Properties & $D-40$ & $\begin{array}{l}\text { (Grade } \\
\text { D-55 } \\
\text { (DYNH) }\end{array}$ & $\begin{array}{l}\text { Designation } \\
\qquad \text { D-70 }\end{array}$ & n of Poly & thylene $\mathrm{R}$ & Resins) & $D-145$ & Test Method \\
\hline Molecular weight, average & $14-$ & $18-$ & $20-$ & $24-$ & 26- & $28-$ & $30-$ & -- \\
\hline & 18,000 & 20,000 & 22,000 & 26,000 & 28,000 & 30,000 & 32,000 & \\
\hline Specific gravity & 0.92 & 0.92 & 0.92 & 0.92 & 0.92 & 0.92 & 0.92 & \\
\hline \multicolumn{9}{|l|}{ Stiffness in flexure, p.s.i. } \\
\hline $25^{\circ} \mathrm{C}$ & 18,000 & 18,000 & 18,000 & 18,000 & 18,000 & 18,000 & 18,000 & A.S.T.M. D747-43T \\
\hline $0^{\circ} \mathrm{C}$ & 30,000 & 30,000 & 30,000 & 30,000 & 30,000 & 30,000 & 30,000 & A.S.T.M. D747-43T \\
\hline$-25^{\circ} \mathrm{C}$ & 66,000 & 66,000 & 66,000 & 66,000 & 66,000 & 66,000 & 66,000 & A.S.T.M. D747 (Tentative) \\
\hline$-50^{\circ} \mathrm{C}$ & 160,000 & 160,000 & 160,000 & 160,000 & 160,000 & 160,000 & 160,000 & A.S.T.M. D747 (Tentative) \\
\hline Yield strength at $25^{\circ} \mathrm{C}$, p.s.i. & 1,430 & 1,480 & 1,490 & 1,600 & 1,700 & 1,830 & 1,720 & A.S.T.M. D412-41 \\
\hline Tensile strength, p.s.i. & 1,430 & 1,825 & 1,965 & 2,435 & 2,965 & 3,160 & 3,060 & A.S.T.M. D412-41 \\
\hline Compressive strength, p.s.i. & - & 3,000 & -- & -- & -- & -- & -- & -- \\
\hline Ultimate elongation at $25^{\circ} \mathrm{C}$, \% & 305 & 560 & 550 & 560 & 580 & 605 & 625 & A.S.T.M. D412-41 \\
\hline \multirow[t]{2}{*}{ Brittle temperature, ${ }^{\circ} \mathrm{C}$} & -55 & Below & Below & Below & Below & Below & Below & A.S.T.M. D746-43T \\
\hline & & -70 & -70 & -70 & -70 & -70 & -70 & \\
\hline Impact strength, ft. $-1 \mathrm{~b} . / \mathrm{in}$. & - & $>3$ & -- & -- & - & - & $\ldots$ & A. S. T.M. D256-43T (A) \\
\hline Tear strength, p.s.i. & 440 & 500 & 540 & 560 & 580 & 605 & 690 & A.S.T.M. D256-41T \\
\hline Abrasion volume loss & & & & & & & & \\
\hline$($ standard butyl rubber $=100)$ & 85 & 55 & 50 & 45 & 40 & 35 & 30 & $142 a$ \\
\hline Hardness Durometer D at $25^{\circ} \mathrm{C}$ & $52-54$ & $52-54$ & $52-54$ & $52-54$ & $52-54$ & $52-54$ & $52-54$ & -- \\
\hline
\end{tabular}




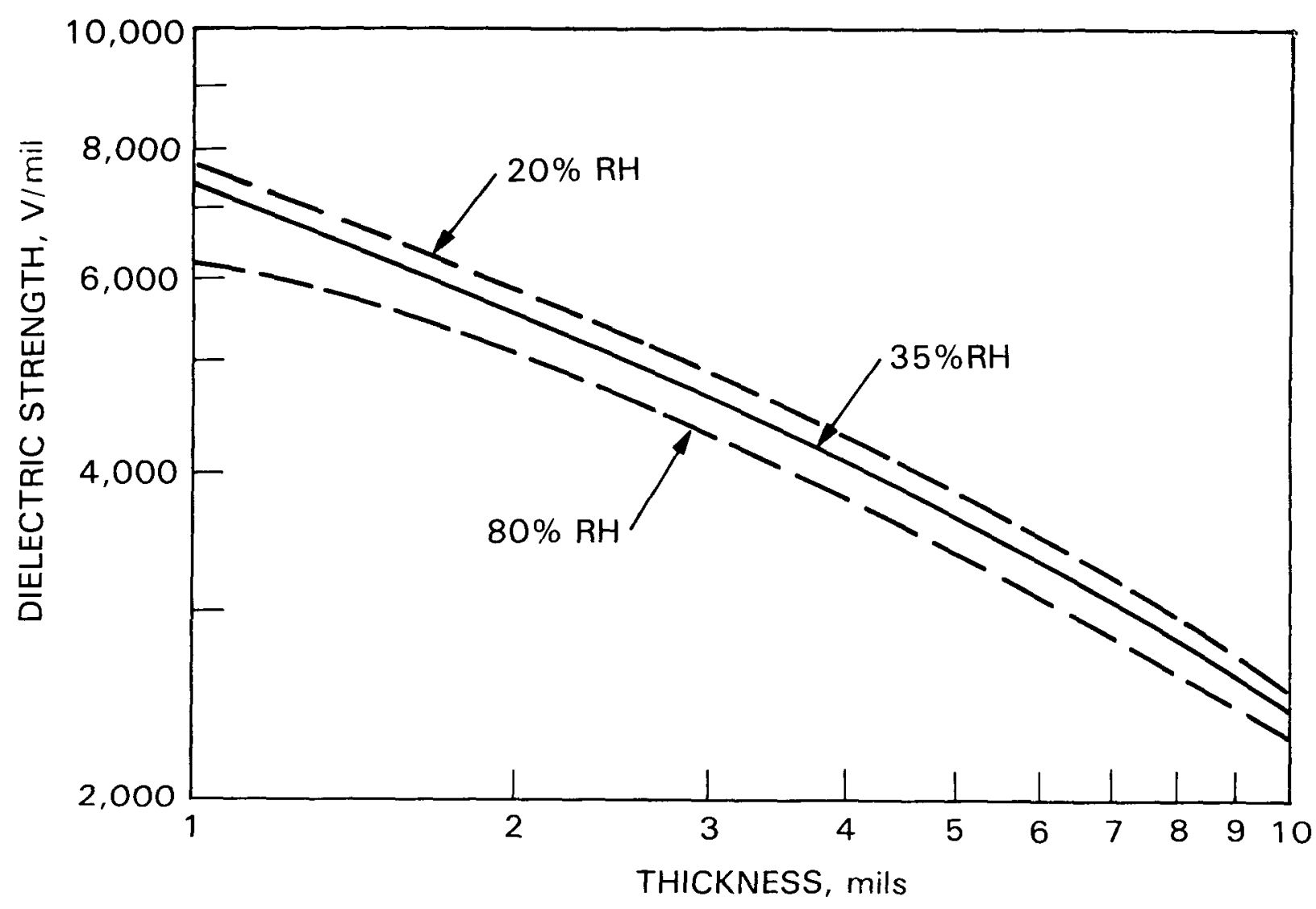

Figure 15. Dielectric Strength of Mylar Film Material at Various Humidities (After Du Pont Co. Technical Bulletin M-4D, "Electrical Properties of Mylar Polyester Film")

4. Buried Cable

Most commercial cables intended for buried application are rated at, and operate at, $15 \mathrm{kV}$ and 60 hertz (Reference 26). The polyethylene insulation surrounding the conducting core is about $175 \mathrm{mils}$ thick. When new, the average voltage at breakdown $V_{A}$ of the 175-mil-thick polyethylene insulation is about 800 volts/mil, and in service, the cables operate with an average voltage gradient $(\mathrm{V} / \mathrm{t})$ across the insulation of about $85 \mathrm{volts} / \mathrm{mil}$, for a safety margin of about 10 to 1 .

With this information, an estimate of the initial intrinsic dielectric strength of the polyethylene insulation material perpendicular to the cable axis can be made using the tip-to-ground equation given in Table 3. For this calculation, $V_{A}=800 \mathrm{volts} / \mathrm{mil}, t=175 \mathrm{mils}$, and $\mathrm{R}=1.20 \mathrm{mils}$. Thus, $(\mathrm{dV} / \mathrm{dy})_{\mathrm{MAX}}$ is estimated at $36,742 \mathrm{volts} / \mathrm{mil}$, which, when compared with the isotropic, unoriented value of $7378 \mathrm{volts} / \mathrm{mil}$, indicates about a five-times orientation of the polyethylene material, which may be associated with the cable manufacturing process.

Next the average voltage gradient that is associated with the proportional limit can be calculated. This would be the maximum service level to 
keep the electrical-field-induced mechanical stresses at or below the proportional limit, which also keeps the mechanical-stress levels from being in the ductile region of polyethylene. For this calculation, $(\mathrm{dV} / \mathrm{dy})=2582$ volts $/ \mathrm{mil}, t=175 \mathrm{mils}$, and $R=1.20 \mathrm{mils}$. This value of $R$ would be associated with a local site of high field intensity, which could be scratches, nicks, burrs, dents or other non-smooth surface features on the core conductor. It is also possible that embedded particles could act as focal sites for field intensification. Carrying out the calculation, the average voltage gradient associated with the proportional limit is 56 volts/mil. Despite the conventional 10-to-1 safety margin, this calculation strongly suggests that the service environment is imposing electrical field-induced mechanical loads above the proportional limit of polyethylene, and in the ductile region.

Under these mechanical loads, it can be expected that time-dependent ductile response will occur, causing a reorientation of the polyethylene insulation material from its initial direction parallel with the cable axis to a direction perpendicular to the cable axis. It can further be suspected that the rate of reorientation will be highest at the interfacial surface of polyethylene immediately adjacent to the site of high field intensity, that is, the highest mechanical stress, and that it will fall off progressively through the bulk in relation with outward spatial tapering of the field intensity.

This reorientation would constitute a PHYSICAL AGING process, with at least two associated consequences. First, reorientation to a direction perpendicular to the cable axis would cause a gradual reduction in the dielectric strength in that direction. Given a near-five-times manufacturing orientation, and if bulk reorientation were to approach the isotropic state, then it $c$ an be predicted that the average voltage-at-breakdown measured across the insulation could gradually decay from an initial value of 800 volts/mil to a lower value in the order of 160 volts/mil. However, local surface reorientation at the site of high field intensity would be expected to be greater than the average bulk reorientation.

Second, the reorientation would be expected to produce a change in the optical birefrigence of the polyethylene material. It can be strongly speculated that electrical trees, as first reported by Kitchin (Reference 27) and later by others (References 28, 29), and which are revealed on stained specimens in optical microscopy are a manifestation of reorientation induced optical berefrigence. As such, they would reflect mophological changes at the surface and in the bulk material, and would not be cavities, voids, or filamentary tunnels. Indeed the appearance of an electrical tree defined by this morphological consideration could bridge across the entire thickness of the insulation, but would not be in itself any manifestation of actual electrical breakdown. It precedes electrical breakdown by revealing stress reorientation, which would also result in a lower value of dielectric strength, as compared with that of a freshly manufactured cable. Dissado et al (Reference 30 ) have reported that electrical trees (they called them water trees) can cross the entire thickness of polyethylene specimens without an associated breakdown.

With respect to actual failure, it can be expected that the polyethylene material immediately adjacent to the site of high field intensification would experience the greatest degree of local reorientation, compared with locations 
away from the site where the field intensities become progressively lower. With continuing local reorientation, the associated intrinsic dielectric strength for voltage breakdown continues to decrease until a critical value is reached. This initiates breakdown, which then propagates catastrophically. As observed in Figure 15, absorbed water in Mylar reduces its voltage-at-breakdown by about $15 \%$. Thus, absorbed water in the buried cables can act to exacerbate failure behavior by lowering the critical value of $(\mathrm{dV} / \mathrm{dy})$ required for failure initiation. This becomes especially serious if ground water finds its way to the interface between the conducting core and the polyethylene insulation, for it is also at this interface that the maximum field intensities are expected to be found.

It should not be overlooked that the critical value of the intrinsic dielectric strength for voltage breakdown of the locally reoriented polyethylene may be at a marginal level, when addressing underground service operations as compared with those above ground. In the ground, absorbed water reduces the critical value below the service stresses, and thus failures occur; whereas above ground in drier conditions, the critical value may remain marginally above the service stresses.

Last, there are three other matters to be considered: temperature, crosslinking, and anti-tree agents. First, increases in cable operating temperatures would increase the rate of ductile response leading to faster stress reorientation. Thus times to failure would be expected to decrease with increasing cable operating temperature, as reported in Reference 26.

Second, crosslinking of the polyethylene occurs throughout the bulk, but the local reorientation leading to failure initiation would occur at the surface of the polyethylene immediately adjacent to the site of the high field intensification. Bulk crosslinking may not be effective in retarding or stopping a surface behavior. Along these lines, it should be noted that the physical state or morphology of crystalline polymers such as polyethylene, polypropylene, etc., can be quite different at surfaces as compared with those in the bulk. It often happens that if melted polymers are adjacent to metallic surfaces during cooling from the melt, the crystalline character of the surface is different from the bulk crystalline state. This surface behavior has been termed "transcrystallinity," and Shaner and Corneliussen (Reference 31) observed such behavior for polypropylene insulation around a copper core. The surface properties and bulk properties were different. Dissado et al (Reference 30 ) have reported similar observations with polyethylene insulation material. The point is that the dielectric strength behavior of the surface material adjacent to the conducting core, where failure would initiate, may be not only different from the bulk, but surface transcrystallinity effects may resist crosslinking efforts. Thus the failure potential is essentially unchanged as compared with that of uncrosslinked polyethylene insulation. Bahder et al (Reference 26) report that crosslinked polyethylene cables fail in service.

Third, anti-tree agents might be compounding additives that act to raise the dielectric-strength properties of polyethylene, thus countering any reductions that would be caused by water. Figure 16 is adapted from Du Pont technical bulletin M-4D illustrating for Mylar that transformer oil decreases its dielectric-strength properties, but Freon C-318 increases its dielectricstrength properties. 


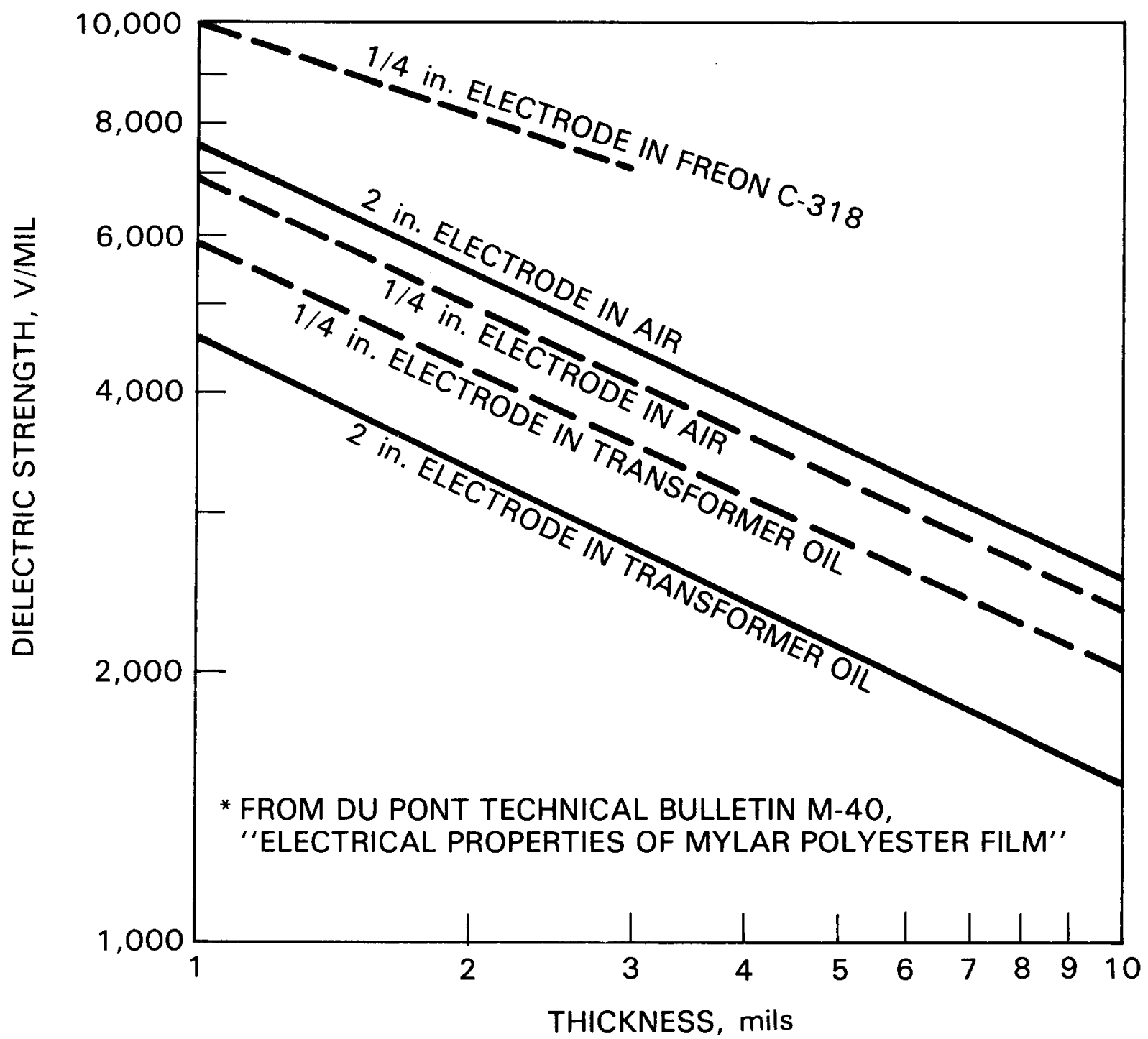

Figure 16. Effect of Electrode Size on Dielectric Strength of Mylar (After Du Pont Co. Technical Bulletin M-4D, "Electrical Properties of Mylar Polyester Film") 


$$
7
$$


This concept indicates that the intrinsic dielectric strengths of electrical insulation materials have numerically the value of a potential gradient $(\mathrm{dV} / \mathrm{dy})$, which can be generated from experimental measurements of average breakdown voltage as a function of sample thickness $t$. The action of an electrical field is to impose a local mechanical stress on the material surface, which becomes the initiating mechanism of failure when the generated voltage stress gradient equals or exceeds the intrinsic dielectric strength. This is followed by fracture propagation driven by electrical-field-induced mechanical stresses in the material bulk. Associated with mechanical failure is the release of charged particles and electrons along the fracturing interface, detected as electrical current in the electrode circuitry. A mechanical failure concept permits use of the material property called the proportional limit to define voltage design limits for insulation materials in electrical service.

A corollary of this concept is the apparent identification of an effective radius of curvature associated with nicks, edges, and corners on conducting surfaces, and with contact-style electrodes used for voltage breakdown testing.

The dielectric-strength properties of insulation materials appear to be orientation-sensitive, and this feature, along with the use of ( $\mathrm{dV} / \mathrm{dy}$ ) as the intrinsic dielectric strength and the effective radius of curvature, leads to agreement in dielectric data measured by differing techniques such as recessed specimens and contact-style electrodes. In addition, a basis was provided for offering a possible explanation of the cause of failures in buried polyethylene-insulated high-voltage cables, and for electrical trees (water trees) produced in the material during service.

What primarily emerges from the scope of the overall concept is that imposing electrical-field-induced mechanical stresses on a material in the stress region between the material's proportional limit and ultimate stress will produce service problems, no matter how manifested. This document emphasizes effects on polyethylene because of their immediate relevance to buried-cable failures, but all other industrially used insulation materials would be expected to conform to these concepts.

For example, Shibuya et al (Reference 32) investigated for the voltage levels necessary to generate voids in epoxy insulating resins. They normalized all of their experimental data to a voltage stress gradient $(\mathrm{dV} / \mathrm{dy})$, and observed that whenever $(\mathrm{dV} / \mathrm{dy})$ exceeded $3 \times 10^{8} \mathrm{~V} / \mathrm{m}$ $(7.5 \mathrm{kV} / \mathrm{mil})$, voids occurred, and no voids occurred at (dV/dy) values less than $3 \times 10^{8} \mathrm{~V} / \mathrm{m}$. This is consistent with the concepts described here, and therefore the value of $(\mathrm{dV} / \mathrm{dy})=3 \times 10^{8} \mathrm{~V} / \mathrm{m}$ could be interpreted as the electrical-stress proportional limit for the epoxy resins they studied. 


\section{REFERENCES}

1. Cuddihy, E., et al., Photovoltaic Module Encapsuluation Design and Materials Selection: Volumes I and II, JPL Publication 81-102, JPL Document No. 5101-177, DOE/JPL-1012-56, and JPL Publication 84-34, JPL Document No. 5101-237, DOE/JPL-1012-97, Jet Propulsion Laboratory, Pasadena, California, June 1, 1982, and June 1, 1984.

2. Cuddihy, E., et al., "Applications of Ethylene Vinyl Acetate as an Encapsulation Material for Terrestrial Photovoltaic Modules," JPL Publication 83-35, JPL Document No. 5101-220, DOE/JPL-1012-87, Jet Propulsion Laboratory, Pasadena, California, April 15, 1983.

3. E.g., Conference Records of the IEEE International Symposia on Electrical Insulation for the Years 1976 to 1982, published and sponsored by the IEEE Electrical Insulation Society.

4. Kallis, J.M., Trucker, D.C., Cuddihy E.F., and Garcia, A., "Multidimensional Effects on the Electrical Isolation Capability of Photovoltaic Modules," accepted for 1984 publication in Solar Cells.

5. Tests for Dielectric Breakdown Voltage and Dielectric Strength of Electrical Insulating Materials at Commercial Power Frequencies, ASTM-D-149-64, American Society for Testing Materials, 1970.

6. Mason, J.H., "Breakdown of Solid Dielectrics in Divergent Fields," proceedings I.E.E., Monograph No. 127M, 102C, p. 254, Institution of Electrical Engineers, London, 1955.

7. Ashcraft, A.C., Eichhorn, R.M., and Shaw, R.G., "Laboratory Studies of Treeing in Solid Dielectrics and Voltage Stabilization of Polyethylene," conference record of 1976 IEEE International Symposium on Electrical Insulation, sponsored by the IEEE Electrical Insulation Society, p. 213, Institute of Electrical and Electronics Engineers, Inc., New York, 1976.

8. Pillai, A.S., and Hackam, R., "Electric Field and Potential Distributions for Unequal Spheres Using Symmetric and Asymmetric Applied Voltages," IEEE Transactions on Electrical Insulation, Vol. EI-18, No. 5, p. 477, Institute of Electrical and Electronics Engineers, Inc., New York, 1983.

9. Dreyfus, L., "Uber die Anwendung der Theorie der Konformen Abbildung zur Berechung der Durchschlags - und Uberschlagsspannung Zwischen Kantigen Konstruktionsteilen Unter 01," Archiv fur Elektrotechnik, Band XIII, 123 (1924).

10. Cockcroft, J.D., "The Effect of Curved Boundaries on the Distribution of Electrical Stress Round Conductors," J. Institution of Electrical Engineers, London, Vo1. 66, p. 385 (1928).

11. Bouwers, A., and Cath, P.G., "The Maximum Electrical Field Strength for Several Simple Electrode Configurations," Philips Technical Review, vol. 6, No. 9, p. 270, September, 1941. 
12. Dickenson, J.T., and Jensen, L.C., "Crack Velocity Dependence of Electron Emission During Fracture of Filled Elastomers," J. Polymer Science, Polymer Physics Edition, Vol. 20, p. 1925, 1982.

13. Whitehead, S., Dielectric Breakdown of Solids, Oxford at the Clarendon Press, London, 1951 .

14. Swanson, J.W., and Da11, F.C., "On the Dielectric Strength of Synthetic Electrical Insulating Materials," Conference Record of 1976 IEEE International Symposium on Electrical Insulation, sponsored by the IEEE Electrical Insulation Society, p. 196, Institute of Electrical and Electronics Engineers, Inc., New York, 1976.

15. Cuddihy, E.F., "Solvent-Sensitivity of Biaxially Oriented Poly(Ethylene Terephthalate) Film," Polymer Letters Edition, Vol. 13, p. 595, 1975.

16. Andrews, E.H., Fracture in Polymers, American E1sevier, New York, 1968.

17. Oakes, W.G., "The Intrinsic Electric Strength of Polythene and its Variation with Temperature," proc. I.E.E., Vol. 95, Part i, p. 36, Institution of Electrical Engineers, London, 1948.

18. Bird, D.W., and Pelzer, H., "A Note on Crystallite Size and Intrinsic Electric Strength of Polythene," Proc. I.E.E., Vol. 96, Part i, p. 44, Institution of Electrical Engineers, London, 1949.

19. Oakes, W.G., "The Electric Strength of Some Synthetic Polymers, "Proc. I.E.E., Vol. 96, Part i, p. 37, Institution of Electrical Engineers, London, 1949.

20. Austen, A.E.W., and Pelzer, H., "The Electric Strength of Paraffins and Some High Polymers," J.I.E.E., Vol. 89, Part i, p. 525, Institution of Electrical Engineers, London, 1946.

21. Heffelfinger, C.J., and Knox, K.L., The Science and Technology of Polymer Films, Vol. II, Chapter 14, 0.J. Sweeting, Editor, Wiley-Interscience, New York, 1971.

22. Batra, S.K., and Nuruzzaman, S., "Elastic-Inelastic Behavior of PET [Poly(Ethylene Terephthalate)] and Nylon 66 Monofilaments Under Lateral Compression," J. Polymer Science, Polymer Physics Edition, Vol. 13, p. 369,1975 .

23. Raff, R.A.V., and Allison, J.B., Polyethylene, High Polymer Series, Vol. XI, Interscience Publishers, Inc., New York, 1956.

24. Dakin, T.W., and Studniarz, S.A., "The Voltage Endurance of Cast and Molded Resins," Proceedings, 13th Electrical/Electronics Insulation Conference, Chicago, 1977, p. 318-21, Institute of Electrical and Electronics Engineers, Inc., New York, 1977.

25. Pattini, G., and Simoni, L., "Discussion on Modeling of Voltage Endurance," 3d International Symposium on Electrical Insulation, Conference Record, Institute of Electrical and Electronics Engineers, Inc., New York, p. 15, 1980. 
26. Bahder, G., et a1, "Life Expectancy of Crosslinked Polyethylene Insulated Cables Rated 15 to $35 \mathrm{kV}$," IEEE Transactions on Power Apparatus and Systems, Vol. PAS-100, No. 4, p. 1581, Institute of Electrical and Electronics Engineers, Inc., New York, 1981.

27. Kitchin, D.W., and Pratt, O.S., "Internal Corona Spaces in Cables," American Institute of Electrical Engineers, Transactions, 76 (pt. III), 1066-72, 1957; "Treeing in Polyethylene as a Prelude to Breakdown," ibid., 77 (pt. III), 180-6, June 1958.

28. Vah1strom Jr., W. "Investigation of Insulation Deterioration in $15 \mathrm{kV}$ and $22 \mathrm{kV}$ Polyethylene Cables Removed from Service," IEEE Trans., PAS Vo1. 91, pp. 1023-1028, Institute of Electrical and Electronics Engineers, Inc., New York, May/June 1972.

29. Lawson, J.H., and Vahlstrom, W., Jr., "Investigation of Insulation Deterioration in $15 \mathrm{kV}$ and $22 \mathrm{kV}$ Polyethylene Cables Removed from Service, Part II," IEEE Trans. PAS Vo1. 92, pp. 824-831, Institute of Electrical and Electronics Engineers, Inc., New York, March/April 1973.

30. Dissado, L.A., Wolfe, S.V., and Fothergill, J.C., "A Study of the Factors Influencing Water Tree Growth," IEEE Transactions on Electrical Insulation, Vol. EI-18, No. 6, Institute of Electrical and Electronics Engineers, Inc., New York, December, 1983.

31. Shaner, J.R., and Corneliussen, R.D., "Transcrystalline Growth at an Internal Surface," J. Polymer Science, Part A-2, p. 1611, 1972.

32. Shibuya, Y., Zoleoziowski, S., and Calderwood, J.H., "Void Formation and Electrical Breakdown in Epoxy Resins," IEEE Transactions on Power Apparatus and Systems, Vo1. PAS-96, No. 1, p. 198, Institute of Electrical and Electronics Engineers, Inc., New York, 1977. 


\begin{abstract}
APPENDIX A
SERIES EXPANSIONS OF THE TIP-TO-TIP AND TIP-TO-GROUND ANALYTICAL

EXPRESSIONS IN TABLE 3
\end{abstract}

Tip-To-Tip

The tip-to-tip equation is:

$$
(d V / d y)_{\text {MAX }}=\frac{V_{A} t\left(1+2 R / t^{1 / 2}\right.}{2 R \tanh ^{-1}[t /(t+2 R)]^{1 / 2}}
$$

which can be rearranged algebraically to the following form:

$$
\frac{(d V / d y)_{\text {MAX }}}{V_{A}}=\frac{\left(\frac{t}{2 R}\right)(1+2 R / t)^{1 / 2}}{\tanh ^{-1}\left[\frac{1}{(1+2 R / t)}\right]^{1 / 2}}
$$

It is convenient to define the variable expression

$$
x=(1+2 R / t)^{-1 / 2}
$$

which when substituted into Equation A-2 yields

$$
\frac{(d V / d y)}{V_{A}}=\frac{(t / 2 R)(1 / x)}{\tanh ^{-1}(x)}
$$

From reference handbooks, the series expression for the inverse hyperbolic tangent, $\tanh ^{-1}(x)$, is:

$$
\tanh ^{-1}(x)=x+\frac{x^{3}}{3}+\frac{x^{5}}{5}+\frac{x^{7}}{7}+\ldots . .
$$

which can be divided into the numerator term of Equation $A-4,1 / x$, to yield

$$
\frac{(1 / x)}{\tanh ^{-1}(x)}=\frac{1}{x^{2}}-\frac{1}{2}-\frac{4}{45} x^{2}-(\text { higher powers of } x)
$$


From Equation $A-3, x^{2}=(1+2 R / t)^{-1}$, and therefore $\left(1 / x^{2}\right)=(1+2 R t)$, which when both are substituted into Equation $A-6$, and then into Equation $A-4$, will yield sequentially as Equations $A-7, A-8$, and A-9:

$$
\begin{gathered}
\frac{(d V / d y)_{M A X}}{V_{A}}=\left(\frac{t}{2 R}\right)\left(\frac{1}{x^{2}}-\frac{1}{3}-\frac{4}{45} x^{2}-. . \cdot\right) \\
\frac{(d V / d y)_{M A X}}{V_{A}}=\left(\frac{t}{2 R}\right)\left(1+\frac{2 R}{t}-\frac{1}{3}-\frac{4}{45(1+2 R / t)}-\cdots \cdot\right) \\
\frac{(d V / d y)_{\text {MAX }}}{V_{A}}=\left(\frac{t}{2 R}\right)\left(\frac{2 R}{t}+\frac{2}{3}-\frac{4}{45(1+2 R / t)}-\cdots \cdot \cdot\right)
\end{gathered}
$$

When $(t / 2 R)$ is multiplied into each term of the series expression in Equation $A-9$, the third term as well as all higher terms become numerically negligible for small $t$ or large $R$; therefore Equation A-9 reduces to

$$
\frac{(\mathrm{dV} / \mathrm{dy})_{\text {MAX }}}{\mathrm{V}_{\mathrm{A}}}=1+t / 3 \mathrm{R}
$$

Taking the reciprocal of Equation $A-10$, and moving out the term $3 R$ algebraically, yields the final expression shown as Equation 10 in the text:

$$
\mathrm{V}_{\mathrm{A}}=(\mathrm{dV} / \mathrm{dy})_{\mathrm{MAX}}=(3 \mathrm{R})(t+3 \mathrm{R})^{-1}
$$

\section{Tip-To-Ground}

The tip-to-ground equation is

$$
(\mathrm{dV} / \mathrm{dy})_{\operatorname{MAX}}=2 \mathrm{v}_{\mathrm{A}} \mathrm{tP} / \ln (\mathrm{Q})
$$

and

$$
\begin{aligned}
& P=(t+R / t)^{1 / 2} / R \\
& Q=\left[2 t+R+2 t^{1 / 2}(t+R)^{1 / 2}\right] / R
\end{aligned}
$$


$Q$ can be re-expressed as

$$
Q=\left[t+2 t^{1 / 2}(t+R)+(t+R)\right] / R
$$

where it can be recognized as the binomial expression

$$
Q=\left[t^{1 / 2}+(t+R)^{1 / 2}\right]^{2 / R}
$$

It is convenient to define $\alpha=t / R$, which upon substitution into Equation $A-14$ yields

$$
Q=\left[\alpha^{1 / 2}+(\alpha+1)^{1 / 2}\right]^{2}
$$

Exclusive of $v_{A}$, the numerator term of Equation $A-12$, is $2 t P$, which, using the definition $\alpha=t / R$, results algebraically in the following:

$$
2 t P=2 \alpha^{1 / 2}(\alpha+1)^{1 / 2}
$$

Upon substituting Equation A-15 and Equation A-16 into Equation A-12, the following algebraic steps can be carried out:

$$
\begin{gathered}
\frac{(\mathrm{dV} / \mathrm{dy})_{\mathrm{MAX}}}{\mathrm{V}_{\mathrm{A}}}=\frac{2 \alpha^{1 / 2}(\alpha+1)^{1 / 2}}{\ln \left[\alpha^{1 / 2}+(\alpha+1)^{1 / 2}\right]^{2}} \\
\frac{(\mathrm{dV} / \mathrm{dy})_{\mathrm{MAX}}}{\mathrm{V}_{\mathrm{A}}}=\frac{2 \alpha^{1 / 2}(\alpha+1)^{1 / 2}}{2 \ln \left\{(\alpha+1)^{1 / 2}\left[1+\frac{\alpha}{\alpha+1}\right]^{1 / 2}\right\}} \\
\frac{(\mathrm{dV} / \mathrm{dy})_{\operatorname{MAX}}}{\mathrm{V}_{\mathrm{A}}}=\frac{\alpha^{1 / 2}(\alpha+1)^{1 / 2}}{\frac{1}{2} \ln (1+\alpha)+\left[1 \mathrm{n} 1+\left(\frac{\alpha}{\alpha+1}\right)^{1 / 2}\right]}
\end{gathered}
$$


The numbered term $(\alpha+1)^{1 / 2}$ can be expanded into a series using the wel1known series expansion

$$
(1+x)^{n}=1+n x+\frac{n(n-1) x^{2}}{2}+\frac{n(n-1)(n-2)}{6} x^{3}+\cdots \cdots
$$

and the denominator terms can be expanded into a series using the well-known series expansion

$$
\ln (1+x)=x-\frac{1}{2} x^{2}+\frac{1}{3} x^{3}-\frac{1}{4} x^{4}+\cdots \cdot
$$

So doing, and drawing together all the terms, yields

$$
\frac{(\mathrm{dV} / \mathrm{dy})_{\operatorname{MAX}}}{\mathrm{V}_{\mathrm{A}}}=\frac{\alpha^{1 / 2}\left(1+\frac{1}{2} \alpha-\frac{1}{8} \alpha^{2}+\frac{1}{16} \alpha^{3} \cdot . \cdot\right)}{\alpha^{1 / 2}\left(1-\frac{1}{6} \alpha+\frac{3}{40} \alpha^{2}-\frac{5}{112} \alpha^{3}+. . \cdot\right)}
$$

dividing the numerator by denominator rèsults in

$$
\frac{(\mathrm{dV} / \mathrm{dy})_{\mathrm{MAX}}}{\mathrm{V}_{\mathrm{A}}}=1+\frac{2}{3} \alpha-\frac{4}{45} \alpha^{2}+\ldots
$$

now ignoring all terms $\alpha^{2}$ and higher, which become numerically negligible for small values of $t$ or large values of $R$, and substituting for $\alpha$, Equation A-23 becomes

$$
\frac{(\mathrm{dV} / \mathrm{dy})_{\mathrm{MAX}}}{\mathrm{V}_{\mathrm{A}}}=1+\frac{2 \mathrm{t}}{3 \mathrm{R}}
$$

From the series expression shown as Equation A-20, Equation A-24 can also be expressed as

$$
\frac{(d V / d y)_{M A X}}{V_{A}}=(1+t / R)^{2 / 3}
$$


Taking the reciprocal of Equation A-25, and algebraically moving out the variable $R$, yields the final expression shown as Equation 11 in the text:

$$
V_{A}=(d V / d y)_{\operatorname{MAX}}(R)^{2 / 3}(t+R)^{-2 / 3}
$$

\section{SYMMETRY}

It should be noted that the tip-to-tip and tip-to-ground equations used are symmetrically related, with the midpoint (see Figure $A-1$ ) between the two needle tips being the ground plane for the tip-to-ground equation.

This is demonstrated by substituting $V / 2$ and the gap variable $\tau=t / 2$ in the tip-to-tip Equation $A-1$, yielding

$$
\frac{\mathrm{d}(\mathrm{V} / 2) / \mathrm{d}(\tau / 2)}{(\mathrm{V} / 2) /(\tau / 2)}=\frac{\mathrm{d} V}{\mathrm{~d} \tau}=\frac{\tau(1+\mathrm{R} / \tau)^{1 / 2}}{\mathrm{R} \tanh ^{-1}[\tau /(\tau+\mathrm{R})]^{1 / 2}}
$$

The right-hand term of Equation $A-27$ can be rearranged to

$$
\frac{d V}{d \tau}=\frac{(1+R / \tau)^{1 / 2}}{R \tanh ^{-1}\left[\frac{1}{(1+R / \tau)^{1 / 2}}\right]}
$$

and using the mathematical identity

$$
\tanh ^{-1}\left(\frac{a}{x}\right)=\frac{1}{2} \ln \left[\frac{x+a}{x-a}\right]
$$

results in

$$
\frac{(\mathrm{dV} / \mathrm{d} \tau)_{\operatorname{MAX}}}{(\mathrm{V} / \tau)}=\frac{2 \tau(1+\mathrm{R} / \tau)^{1 / 2} / \mathrm{R}}{\ln \left[\frac{(1+\mathrm{R} / \tau)^{1 / 2}+1}{(1+\mathrm{R} / \tau)^{1 / 2}-1}\right]}
$$




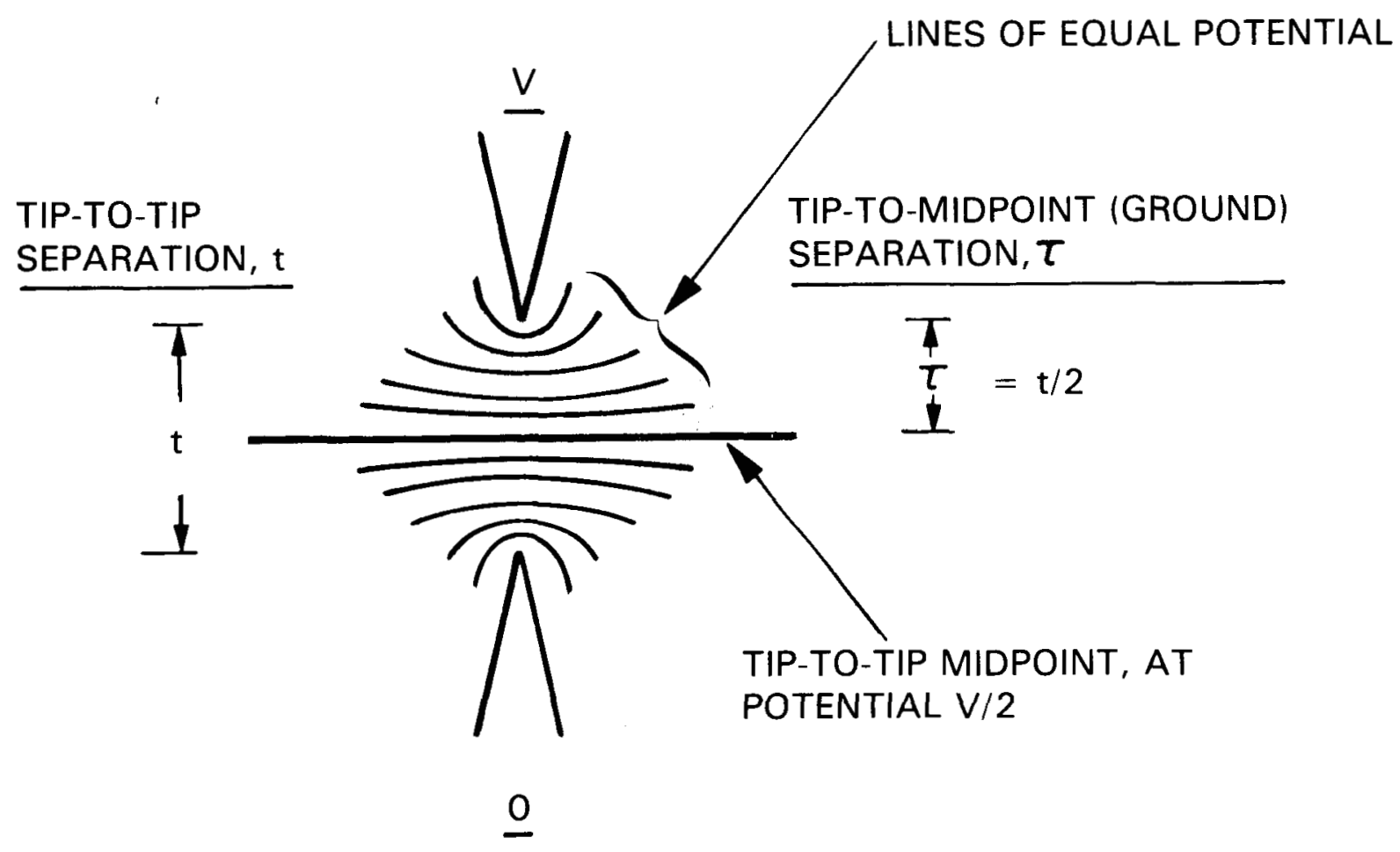

UPPER TIP AT POTENTIAL V

LOWER TIP AT POTENTIAL O

Figure A-1. Geometry of Symmetry Between the Tip-to-Tip and Tip-to-Ground Equations 
The numerator is now recognized as $2 t P$ observed with the tip-to-ground equation, and the remaining step is to transform the denominator algebraically to the $\operatorname{Ln}(Q)$ form also observed with the tip-to-ground equation.

To do this, the top and bottom terms of the natural logarithm expression are each multiplied by $(1+R / \tau)^{1 / 2}+1$, and after rearranging product terms within the natural-logarithm expression, yield

$$
\ln (Q)=\ln \left[\frac{1+R / \tau+2(1+R / \tau)^{1 / 2}+1}{R / \tau}\right]
$$

which then finally becomes

$$
\ln (Q)=\ln \left[\frac{2 \tau+R+2 \tau^{1 / 2}(\tau+R)^{1 / 2}}{R}\right]
$$

Therefore, the convergence expressions for small values of $t$ or large values of $R$ in Equations $A-10$ and $A-24$ are interchangeable using the gap variable $\tau=t / 2$, or $t=2 \tau$. The tip-to-tip convergence expression was found to be

$$
\frac{(d V / d y)}{V_{A A X}}=1+t / 3 R
$$

which, upon substitution of $t=2$, yields

$$
\frac{(\mathrm{dV} / \mathrm{dy})_{\mathrm{MAX}}}{\mathrm{V}_{\mathrm{A}}}=1+\frac{2 \tau}{3 \mathrm{R}}
$$

as derived above. 
$\pm$

구

$\bar{z}$

m

กำ

$\bar{n}$

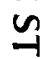

중

Z

고

유

m

莺

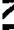

$\geqslant$

$\sum$

5

글

戛 